\title{
Visualization of Proliferative Vascular Endothelial Cells in Tumors in Vivo by Imaging Their Partner of Sld5-1 Promoter Activity
}

Daishi Yamakawa, ${ }^{* \dagger}$ Weizhen Jia, ${ }^{*}$ Hiroyasu Kidoya, ${ }^{*}$ Shoko Hosojima, ${ }^{*}$ Miku Torigata, ${ }^{*}$ Li Zhang, ${ }^{*}$ and Nobuyuki Takakura*

From the Department of Signal Transduction, * Research Institute for Microbial Diseases, Osaka University, Suita; and the Department of Physiology, ${ }^{\dagger}$ Mie University Graduate School of Medicine, Tsu, Japan

Accepted for publication

January 23, 2018.

Address correspondence to Nobuyuki Takakura, M.D., Ph.D., Department of Signal Transduction, Research Institute for Microbial Diseases, Osaka University, 3-1 Yamadaoka, Suita, Osaka 565-0871, Japan. E-mail: ntakaku@biken. osaka-u.ac.jp.

\begin{abstract}
Vascular endothelial cells (ECs) isolated from tumors characteristically express certain genes. It has recently been suggested that tumor vessel normalization facilitates effective drug delivery into tumors; however, how tumor vessel normalization can be recognized on the basis of the molecules expressed by tumor ECs is not clearly defined. The degree of cell proliferation is an important indicator to characterize the condition of the ECs. Herein, we generated transgenic mice expressing enhanced green fluorescent protein (EGFP) under the transcriptional control of the DNA replication factor partner of SId5-1 (PSF1; official name GINS1) promoter to assess whether active ECs can be distinguished from dormant ECs. Predictably, ECs in the adult skin exhibited no EGFP signals. However, after s.c. injection of tumor cells, some ECs shifted to EGFP positivity, enabling distinction of EGFP-positive from EGFPnegative cells. We found that only a fraction of the EGFP-negative ECs strongly expressed the glycosylphosphatidylinositol-anchor protein CD109 associated with the phosphatidylinositol 3-kinase pathway. Taken together, these data indicate that areas of vascular normalization in tumors can be detected by CD109 expression, and this provides a window of opportunity for timing chemotherapy. (Am J Pathol 2018, 188: 1300-1314; https://doi.org/10.1016/j.ajpath.2018.01.015)
\end{abstract}

For suppression of cancer cell proliferation and metastasis, the focus has been on tumor angiogenesis as a therapeutic target. A conventional strategy is to inhibit angiogenesis by blocking angiogenic factors, to reduce the supply of nutrients and oxygen, and to prevent cancer cell invasion through blood vessels. ${ }^{1}$ On the other hand, vascular normalization is proposed as a new therapeutic concept for anticancer therapy, which improves drug delivery into tumor tissues, resulting in tumor regression. ${ }^{2}$ Accordingly, it is necessary to establish endothelial cell characteristics in the tumor to monitor the state of the tumor vasculature precisely.

Endothelial cells (ECs) with at least three different phenotypes can be identified during angiogenesis (namely, so-called tip, stalk, and phalanx cells). ${ }^{3}$ Tip cells possessing filopodia are responsible for determining the direction of migration of newly developing blood vessels. Stalk cells are located behind tip cells and are actively proliferative. ${ }^{4} \mathrm{Pha}-$ lanx cells emerge in the final step during angiogenesis. These latter cells are covered with mural cells, such as pericytes and smooth muscle cells, and contribute to smooth vessel lumen formation by strong cell-cell adhesion via vascular endothelial-cadherin. In addition, vascular ECs exhibit tissue-specific diversity and structural differences (ie, capillary, artery, and vein). ${ }^{5,6}$ Therefore, gene expression in ECs may be modified by the microenvironment in each organ.

A previous report indicated that blood vessel ECs in normal organs and tumor tissues differ in their gene

\footnotetext{
Supported by the Japan Agency for Medical Research and Development Projects for Technological Development, Research Center Network for Realization of Regenerative Medicine and for Development of Innovative Research on Cancer Therapeutics (N.T.), Japan Society for the Promotion of Science grant-in-aid for Scientific Research (A) $15 \mathrm{H} 02545$ (N.T.) and grant-in-aid for Young Scientists (B) JP20631097 (D.Y.), and the Takeda Science Foundation (D.Y.).

D.Y. and W.J. contributed equally to this work.

Disclosures: None declared.
} 
expression profiles. ${ }^{7}$ Particularly, differences in the expression of genes for the cell surface molecules CD276, CD137 (soluble CD137), minK-related peptide 2 (MiRP2), Doppel, protein tyrosine phosphatase receptor type N (PTPRN), CD109, and Ankylosis, the secreted factors Apelin, placenta growth factor (PlGF), and collagen type VIII (Coll VIII) a1, and the intracellular molecules vascular SH2-containing protein (VSCP), phosphatidylinositol-4-phosphate 5-kinase and related FYVE finger-containing proteins signal transduction (ETSvg4), and ubiquitin D have been noted. On the other hand, it has been suggested that blood vessels in the tumor microenvironment are more unstable than in normal organs. However, whether there are gene expression patterns characteristic of such unstable blood vessels in tumors has not been established. Therefore, it would be useful to be able to identify newly developing unstable blood vessels in tumors by gene expressing profiling of ECs.

We previously reported that partner of Sld5-1 (PSF1; official name GINS1), a member of the GINS complex composed of PSF1, PSF2, PSF3, and SLD5, is essential for rapid proliferation of cells, such as epiblasts, with stem cell properties in embryos and for hematopoietic stem cell proliferation during recovery from bone marrow ablation by the anticancer drug 5-fluorouracil (5-FU). ${ }^{8,9}$ PSF1 regulates DNA replication as a member of the GINS complex and functions to regulate chromosomal segregation as a single molecule. On the other hand, cells that are not proliferating express little PSF1 protein, and PSF1 promoter activity is silenced in $G_{0} / G_{1}{ }^{10}$ Therefore, in the present study, we focused on endothelial PSF1 promoter activity in tumors and asked whether quiescent or proliferating cells can be distinguished by any differences in PSF1 promoter activity and specific gene expression patterns in the tumor vasculature.

\section{Materials and Methods}

\section{Mice}

C57BL/6 mice and KSN nude mice (7 to 8 weeks of age) were purchased from Japan SLC (Shizuoka, Japan). To generate PSF1 promoter-enhanced green fluorescent protein (EGFP) mice, previously cloned PSF1 promoter was used. ${ }^{10}$ pBluescript KS + PSF1 promoter-EGFP-neo was cleaved by ApaI and EcoRI, and the purified product was injected into fertilized eggs to generate transgenic mice. Genotyping to confirm the expression of the transgene was performed by PCR using the following primers: forward: 5'-CACATGAAGCAGCACGACTT-3'; reverse: 5'-TGCTCAGGTAGTGGTTGTCG-3' All experiments were performed in accordance with the guidelines of Osaka University Committee for animal and recombinant DNA experiments.

\section{Antibodies}

Anti-GFP antibody (Ab) (MBL, Nagoya, Japan; BioLegend, San Diego, CA), anti-Ki-67 Ab (DakoCytomation, Glostrup,
Denmark; eBioscience, San Diego, CA), anti-chondroitin sulfate protepglycan 4 (NG2) Ab (Millipore, Temecula, CA), anti- $\alpha$-smooth muscle actin-Cy3 Ab (Sigma, St. Louis, MO), anti-F4/80 $\mathrm{Ab}$ (AbD Serotec, Kidlington, UK), anticytokeratin $5 \mathrm{Ab}$ (Abcam, Cambridge, UK), and anti-CD31, anti-CD45, and anti-Ter119 Abs (BD Pharmingen, Franklin Lakes, NJ) were used as the primary Abs in immunofluorescence. Anti-GFP and anti- $\alpha$-smooth muscle actin-Cy3 Abs were diluted 1:500. Other Abs were diluted 1:200. Alexa Fluor 488- or Alexa Fluor 546-labeled goat anti-rabbit and anti-rat IgGs (Molecular Probes, Eugene, OR) and Alexa Fluor 647-labeled goat anti-Armenian hamster IgGs (Jackson ImmunoResearch, West Grove, PA) were used as the secondary Abs (dilution, 1:200). Nuclei were stained by Hoechst or TO-PRO-3 (Molecular Probes) (dilution, 1:1000).

Anti-CD16/32 (Fc-block), anti-rat IgG2a-phycoerythrin (PE), anti-rat IgG2b-PE, anti-CD31-PE, anti-CD45allophycocyanin (BD Pharmingen), anti-rat IgG1-PE, anti-Ki-67-eFluor660, anti-vascular endothelial growth factor receptor 2 (VEGFR2)-PE, anti-CD137-PE, anti-CD276-PE (eBioscience), anti-CD31-Brilliant Violet 421, anti-Tie2-PE, anti- $\alpha 4$ integrin-PE, anti-vascular cell adhesion molecule 1-PE (BioLegend), anti-VEGFR1-PE, anti-Robo4-PE, anti-CD109-PE (R\&D Systems, Minneapolis, MN), anti-rabbit IgG, phosphorylated extracellular signal-regulated kinase (Cell Signaling Technology, Danvers, MA), and Alexa Fluor 647-labeled goat anti-rabbit IgG (Molecular Probes) were used for flow cytometry.

\section{Cell Culture}

Mouse pancreatic endothelial cell line (MS1; ATCC, Manassas, VA), mouse embryonic fibroblast cell line (NIH3T3), mouse melanoma cell line (B16), and mouse Lewis lung carcinoma cell line (LLC; RIKEN Bioresource Centre, Tsukuba, Japan) were grown in Dulbecco's modified Eagle's medium supplemented with $10 \%$ fetal bovine serum and $1 \%$ penicillin/streptomycin (Life Technologies, Carlsbad, CA). The LLC-derived highly metastatic line (Ex3LL; JCRB Cell Bank, Tokyo, Japan) was grown in Hams F10 and L15 (mixed 3:7) medium (Thermo Fisher Scientific, Waltham, MA) supplemented with $10 \%$ fetal bovine serum. Human colorectal adenocarcinoma cell line HT29 (ATCC) was cultured in RPMI 1640 medium with $10 \%$ fetal bovine serum and $1 \%$ penicillin/streptomycin. MS1 cells were used at $1 \times 10^{4}$ cells (sparse seeding) or $5 \times 10^{5}$ cells (for confluence) in 12-well culture plates. After day 2, MS1 cells were used for analysis. Phosphatidylinositol 3-kinase (PI3K) inhibitor LY294002 (Merck, Kenilworth, NJ) was used at $50 \mu \mathrm{mol} / \mathrm{L}$ concentration and cultured for 24 hours with the cells. LLC-Mock and LLC-mouse angiopoietin-1 were established by overexpressing pEGFP-N1 (Clontech, Mountain View, CA) or mouse angiopoietin-1 plasmids. Stable cells were selected using $1 \mathrm{mg} / \mathrm{mL}$ geneticin (Gibco, San Diego, CA). 


\section{Aorta Ring Assay}

Aortas were isolated from 6- to 8-week-old C57BL/6 mice and cut into 0.5 - to 1-mm slices for making aorta rings. Aorta rings were implanted into collagen type I gels (Nitta-gelatin, Osaka, Japan) with $50 \mathrm{ng} / \mathrm{mL}$ human VEGF (PeproTech, Rocky Hill, NJ) and cultured for 1 week in HuMedia-EG2 (Kurabo, Osaka, Japan) with $50 \mathrm{ng} / \mathrm{mL}$ human VEGF. ${ }^{11}$

\section{Matrigel Plug Assay}

Eight-week-old mice were inoculated with $500 \mu \mathrm{L}$ growth factor-reduced Matrigel (BD Biosciences, San Jose, CA) with $150 \mathrm{ng} / \mathrm{mL}$ human VEGF and $30 \mathrm{U} / \mathrm{mL}$ heparin (SigmaAldrich, St. Louis, MO). After 1 week, gels were dissected with skin and fixed with $4 \%$ paraformaldehyde/phosphatebuffered saline for 4 hours at room temperature. After fixation, gels were substituted by $20 \%$ sucrose and mounted with OCT compound (Sakura Finetek Japan, Tokyo, Japan).

\section{Tumor Implantation}

LLC, B16, Ex-3LL, LLC-Mock, or LLC-mouse angiopoietin- 1 tumor cells $\left(1 \times 10^{6}\right.$ per mouse in $0.1 \mathrm{~mL}$ phosphate-buffered saline) were inoculated subcutaneously into wild-type C57BL/6 or PSF1 promoter-EGFP mice ( 7 to 8 weeks of age). For tumor growth inhibition, on day 7 after s.c. inoculation of B16 cells, mice were treated with i.p. injection of saline or $60 \mathrm{mg} / \mathrm{kg}$ body weight 5-FU (Kyowa Hakko Kirin, Tokyo, Japan) every other day. For the detection of the normalization window, a single dose of $5 \mathrm{mg} / \mathrm{kg}$ bevacizumab was injected into KSN nude mice bearing HT29 tumor once the tumor volume had reached 45 to $55 \mathrm{~mm}^{3}$.

\section{Confocal Laser Scanning Microscopy}

Immunostaining was performed as described previously. ${ }^{12}$ The slides were observed under a Leica TCS SP5 Ver1.6 (Leica Microsystems, Wetzlar, Germany) using HC PL APO CS $20 \times 0.7$ DRY. Images were processed using Adobe Photoshop CS5 Extended software (Adobe Systems, San Jose, CA).

\section{Flow Cytometric Analysis and Cell Sorting}

Cultured cells were detached from the culture dish by Versene (Gibco). Mouse tissues were separated by dispase II, collagenase type I, and collagenase type II, as described previously. ${ }^{13}$ Red blood cells were removed from mouse tissues using red blood cell lysis buffer, and cells were reacted with anti-CD16/32 antibody for blocking. Pyronin Y/Hoechst staining was performed as described previously. ${ }^{13}$ Flow cytometric analysis was performed by FACSCalibur (BD Biosciences), and a FACSAria (BD Biosciences) was used for cell sorting. Data analysis was performed by FlowJo7.6 (FlowJo, LLC, San Carlos, CA).

\section{Quantitative Real-Time PCR}

RNA was extracted from cultured cells or sorted cells by using QIAshredder and RNeasy Plus Mini Kit (Qiagen, Hilden, Germany). To generate cDNA, the PrimeScript RT reagent Kit (TaKaRa, Shiga, Japan) was used. Quantitative real-time PCR was performed using the MX3000P Real-Time PCR System (Stratagene, San Diego, CA). Specific primers are used per previous reported sequences or new sequences in this study (Table 1). ${ }^{10,13-24}$

\section{Statistical Analysis}

All experiments were performed in triplicate and repeated at least three times $(n=3)$. All data are displayed as the means $\pm \mathrm{SD}$ and were analyzed by repeated-measures two-way analysis of variance or $t$-tests. $P<0.05$ was considered statistically significant.

\section{Results}

Generation of Mice Expressing EGFP under the Transcriptional Control of the PSF1 Promoter (PSF1 Promoter-EGFP Mice), and Assessment of EGFP Expression in Embryonic Tissues

Mice were generated in which PSF1 promoter activity can be visualized by EGFP expression, and it was tested whether EGFP can mark proliferating cells reflecting stem or progenitor properties. A total of $5.5 \mathrm{~kb}$ of the PSF1 5 -flanking fragment, including the first intron, was used to generate these transgenic mice (Figure 1A). ${ }^{10}$ EGFP transgene expression was confirmed using specific primers (Figure 1B).

The appearance of embryos under stereoscopic fluorescence microscopy revealed stronger EGFP signals at embryonic day 13.5 in the head of transgenic mice than in wild-type mice (Figure 1C). EGFP expression was observed in the ventricular zone of the brain in sections from these transgenic mice (Figure 1D). A previous report had shown that neural progenitor cells in the ventricular zone during embryogenesis undergo expansion. This study had used a fluorescent ubiquitination-based cell cycle indicator (Fucci) system able to visualize the cell cycle without immunostaining. ${ }^{25}$ Therefore, coimmunostaining was performed with the cell proliferation marker Ki-67 and EGFP. Most EGFP signals in cells merged with Ki-67 (Figure 1E). Taken together, these results suggest that PSF1 promoter activity can mark proliferating cells in vivo.

\section{PSF1 Promoter-EGFP Positivity Marks Proliferating} Cells in Adult Tissues

Next, it was assessed whether PSF1 promoter-EGFP-positive cells are present in adult tissues. Intestine and skin was selected because terminally differentiated cells are constantly being 
Table 1 Mouse Primer List

\begin{tabular}{|c|c|}
\hline Gene name & Sequence \\
\hline \multirow[t]{2}{*}{$P^{P S F} 1^{10}$} & F: 5'-CCGGTTGCTTCGGATTAGAG-3' \\
\hline & R: 5'-CTCCCAGCGACCTCATGTAA-3' \\
\hline \multirow[t]{2}{*}{$p 15^{16}$} & F: 5'-AGATCCCAACGCCCTGAAC-3' \\
\hline & R: 5'-CCCATCATCATGACCTGGATT-3' \\
\hline \multirow[t]{2}{*}{$p 16^{16}$} & F: 5'-CGTACCCCGATTCAGGTGAT-3' \\
\hline & R: 5'-TTGAGCAGAAGAGCTGCTACGT-3' \\
\hline \multirow[t]{2}{*}{$p 18^{*}$} & F: 5'-TTTCAAAGACCGATGCGTATCC-3' \\
\hline & R: 5'-CTATGTCAGTATCAGCCAGCAAA-3' \\
\hline \multirow{2}{*}{$p 19^{16}$} & F: 5'-GCCGCACCGGAATCCT-3' \\
\hline & R: 5'-TTGAGCAGAAGAGCTGCTACGT-3' \\
\hline \multirow[t]{2}{*}{$p 21^{*}$} & F: 5'-TAGGGGAATTGGAGTCAGGC-3' \\
\hline & R: 5'-AGAGTGCAAGACAGCGACAA- 3' \\
\hline \multirow[t]{2}{*}{$p 27^{*}$} & F: 5'-AGATACGAGTGGCAGGAGGT-3' \\
\hline & R: 5'-TCTTAATTCGGAGCTGTTTACGTC-3' \\
\hline \multirow[t]{2}{*}{$p 53^{17}$} & F: 5'-AAAGGATGCCCATGCTACAG-3' \\
\hline & R: 5'-TATGGCGGGAAGTAGACTGG-3' \\
\hline \multirow[t]{2}{*}{$p 57^{*}$} & F: 5'-ACCAATCAGCCAGCAGAACA-3' \\
\hline & R: 5'-AGTTGAAGTCCCAGCGGTTC-3' \\
\hline \multirow[t]{2}{*}{ Apelin $^{22}$} & F: 5'-GTTGCAGCATGAATCTGAGG-3' \\
\hline & R: 5'-CTGCTTTAGAAAGGCATGGG-3' \\
\hline \multirow[t]{2}{*}{$P l G F^{14}$} & F: 5'-TTCAGTCCGTCCTGTGTCCTT-3' \\
\hline & R: 5'-ACCACAGCAGCCACTACAGCGACTCA-3' \\
\hline \multirow[t]{2}{*}{ VE-cadherin ${ }^{19}$} & F: 5'-CACTGCTTTGGGAGCCTTC-3' \\
\hline & $\mathrm{R}: 5^{\prime}$-AAGTTAGGGCCTGCCATTG-3' \\
\hline \multirow[t]{2}{*}{ PHD2 ${ }^{13}$} & F: 5'-AGCGAGCGAGAGCTAAAGTAAA-3' \\
\hline & R: 5'-GACGTCTTTGCTGACTGAATTG-3' \\
\hline \multirow[t]{2}{*}{ sFlt1 $1^{13}$} & F: 5'-GAAGACATCCTTCGGAAGCACGAA-3' \\
\hline & 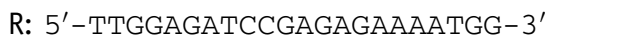 \\
\hline \multirow[t]{2}{*}{ VEGFR $1^{15}$} & F: 5'-CGAACTCCACСTCCATGTTT-3' \\
\hline & R: 5'-TATCTTCATGGAGGCCTTGG-3' \\
\hline \multirow[t]{2}{*}{ VEGFR2 $2^{15}$} & F: 5'-AGAGTTGGTGGAGCATTTGG-3' \\
\hline & R 5'-TAGGCAGGGAGAGTCCAGAA-3' \\
\hline \multirow[t]{2}{*}{ VEGFR3 $3^{19}$} & F: 5'-CGAGGGTGACTACGTGTGTG-3' \\
\hline & R: 5'-ACTTCTTGTGGCAGTGCTTG-3' \\
\hline \multirow[t]{2}{*}{$N r p 1^{19}$} & F: 5'-TGTGGGTACACTGAGGGTCA-3' \\
\hline & R: 5'-CCACCATCCAGACCAGTTG-3' \\
\hline \multirow[t]{2}{*}{$N r p 2^{19}$} & F: 5'-TCATTGAGATTCGGGATGG-3' \\
\hline & R: 5'-CGATGTTCCCACAGTGCTT-3' \\
\hline \multirow[t]{2}{*}{ Tie $2^{21}$} & F: 5'-CGGCTTAGTTCTCTGTGGAGTC-3' \\
\hline & R: 5'-GGCATCAGACACAAGAGGTAGG-3' \\
\hline Notch $1^{13}$ & F: 5'-TGTTGTGCTCCTGAAGAACG-3' \\
\hline & R: 5'-GTGGGAGACAGAGTGGGTGT-3' \\
\hline Jagged $^{19}$ & F: 5'-TGGAGAGCTACAGAATGGGAAC- $3^{\prime}$ \\
\hline & R: 5'-CTTTGAAGTACGTATCACACTCGTC-3' \\
\hline Dll $4^{19}$ & F: 5'-CTGTGTCCCCCAGGCTACTA-3' \\
\hline & R: $5^{\prime}$-CATTGAAGCAGGGTGAGTCC-3' \\
\hline FGFR $1^{19}$ & F: 5'-ACCGAGGACTTTTCTCAGGTC-3' \\
\hline & R: $5^{\prime}-$ CAGCCCGAGTTCCATCAC- $3^{\prime}$ \\
\hline$E d g 1^{15}$ & F: 5'-СTCTGCTCCTGCTTTCCATC-3' \\
\hline & R: 5'-TGATCACCGTCTTCAGCAAG-3' \\
\hline$L I F R^{*}$ & F: 5'-TGAGAACCATGTGGTCGTGT-3' \\
\hline & R: $5^{\prime}$-ATGTACACGACCTGGGAAGC-3' \\
\hline OSMR* & F: 5'-CCAAAAAGAGTTCAGCACACC-3' \\
\hline & R: 5'-CCGACCACACTTGTCTCCAT-3' \\
\hline Ets $1^{24}$ & F: 5'-TCCAGACAGACACCTTGCAG- $3^{\prime}$ \\
\hline & R: 5'-GGTGAGGCGGTCACAACTAT-3' \\
\hline
\end{tabular}

(table continues)
Table 1 (continued)

\begin{tabular}{|c|c|}
\hline Gene name & Sequence \\
\hline \multirow[t]{2}{*}{$P A I-1^{23}$} & F: 5'-ATGGAGCCTTGACAGTGGG-3' \\
\hline & R: 5'-GAGGTCTGGGATGCTGGTT-3' \\
\hline \multirow[t]{2}{*}{ eNOS ${ }^{20}$} & F: 5'-TGAAGATCTCTGCCTCACTCATG- $3^{\prime}$ \\
\hline & R: 5'-AGTCTCAGAGCCATACCAGAATGGTT-3' \\
\hline \multirow[t]{2}{*}{$I L-1 b^{18}$} & F: 5'-TCGTGCTGTCGGACCCATAT-3' \\
\hline & R: 5'-TGTCGTTGCTTGGTTCTCCTT-3' \\
\hline \multirow[t]{2}{*}{$I L-\sigma^{18}$} & F: 5'-GACTTCCATCCAGTTGCCTTCT-3' \\
\hline & R: 5'-AGACAGGTCTGTTGGGAGTGGTA-3' \\
\hline \multirow[t]{2}{*}{$G A P D H^{15}$} & F: 5'-AACTTTGGCATTGTGGAAGG-3' \\
\hline & F: 5'-GGATGCAGGGATGATGTTCT-3' \\
\hline
\end{tabular}

*This work.

$F$, forward; R, reverse.

renewed from stem/progenitor cells in such organs and tissues (ie, small intestinal epithelial cells and keratinocytes, respectively). As expected, EGFP-positive cells were detected in these tissues (Figure 2, A-D). In the intestine, cells located at the crypt are detected as EGFP positive (Figure 2A). On double staining with EGFP and Ki-67, these $\mathrm{EGFP}^{+}$cells near the crypt were also Ki-67 positive (Figure 2B and Supplemental Figure S1A). In the skin, keratinocyte stem cells in the basal layer of the epidermis are EGFP positive (Figure 2C). The $\mathrm{EGFP}^{+}$epithelial cells were identified as cytokeratin 5-positive basal cells (Figure 2D and Supplemental Figure S1B). Thus, we demonstrate that only proliferating cells are positive for EGFP.

To use PSF1 promoter-driven EGFP expression as a marker of proliferating ECs in tumors initiated by s.c. cancer cell inoculation, nonproliferating ECs in the skin should not express EGFP. On double immunostaining with EGFP and the endothelial marker CD31, EGFP expression was lower than the limit of detection (Figure 2E). To exclude this possibility more rigorously, fluorescence-activated cell sorting analysis was performed using CD31 antibody together with the hematopoietic cell marker CD45. Neither $\mathrm{CD} 31^{-} \mathrm{CD} 45^{+}$hematopoietic cells nor $\mathrm{CD} 31^{+} \mathrm{CD} 45^{-} \mathrm{ECs}$ expressed high levels of EGFP in the skin, but doublenegative cells, possibly keratinocyte basal cells (Figure 2C), expressed EGFP (Figure 2F). Hence, it was concluded that the skin vasculature is negative for EGFP. Similarly, little or no EGFP in ECs was detected in other organs (lung, liver, and kidney) (Supplemental Figure S1C). Taking these results together, it is likely that the PSF1 promoter-EGFP mouse model is appropriate for monitoring proliferating ECs in vivo.

\section{PSF1 Promoter Activity Is Up-Regulated in Proliferating ECs}

The level of PSF1 protein expression and PSF1 promoter activity is correlated with cell growth in stem or progenitor cells. ${ }^{8,9}$ In addition, the immortalized fibroblast cell line NIH3T3 also expressed PSF1 protein. ${ }^{10}$ 
A

pBluescript II KS+

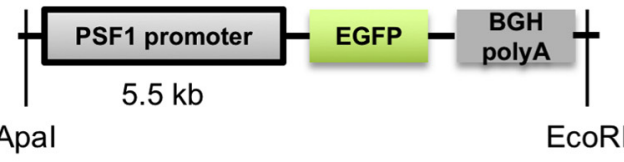

C

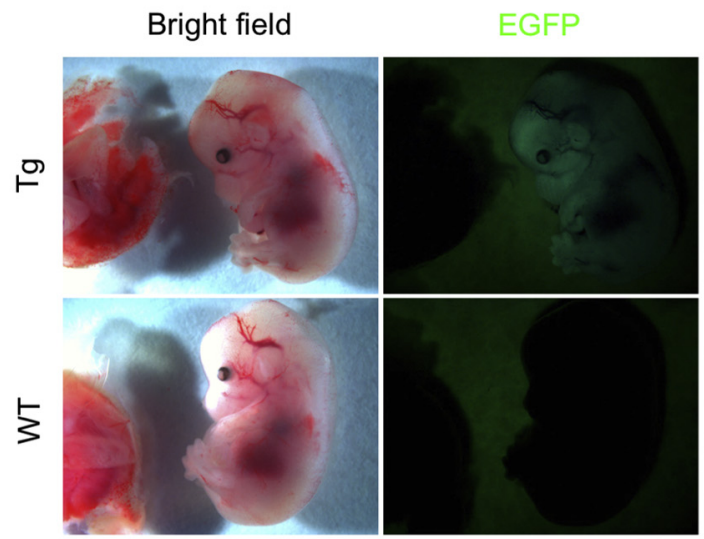

$\mathbf{E}$

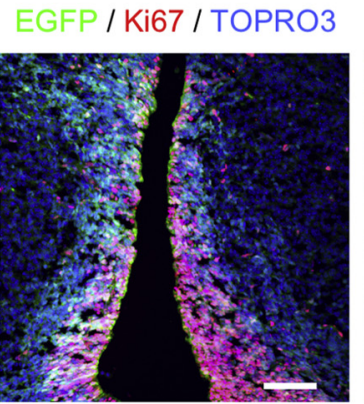

B

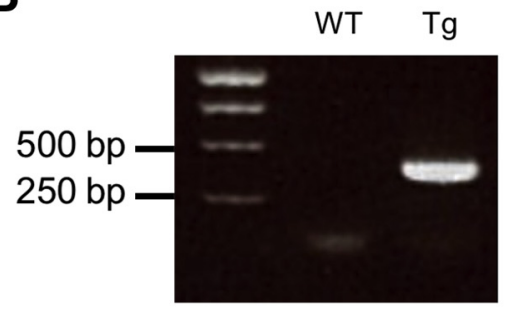

D

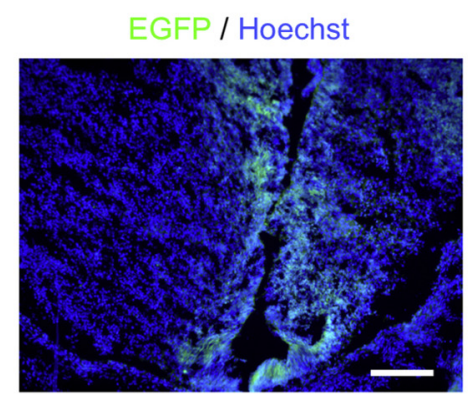

Figure 1 Generation of PSF1 promoter-EGFP mice and correlation between EGFP-positive cells and proliferating cells in embryonic tissue. A: Generation of PSF1 promoter gene fused with gene encoding EGFP. B: Genotyping of transgenic (Tg) mice by RT-PCR. C: Fluorescent stereomicroscopic image by bright field or with GFP filter in embryonic day 13.5 wild-type (WT) or Tg mice. D: EGFP expression in the ventricular zone of head tissue from embryonic day $13.5 \mathrm{Tg}$ mice. E: Immunostaining of proliferating cell marker Ki-67 in the head of embryonic day $13.5 \mathrm{Tg}$ mice. Scale bars: $200 \mu \mathrm{m}$ (D); $100 \mu \mathrm{m}$ (E).

Therefore, it was assessed whether PSF1 mRNA expression is induced when cells proliferate. Cultured NIH3T3 cells and mouse EC MS1 cells both expressed little PSF1 mRNA at confluence, where the cell cycle is arrested, but they up-regulated PSF1 in sparsely seeded cell cultures (Figure 3A). Using Pyronin $\mathrm{Y}$ and Hoechst double staining as a method to analyze the cell cycle (where Pyronin $\mathrm{Y}$ binds to RNA and thus signals RNA synthesis), in sparse cultures, the MS1 line contained both Pyronin $\mathrm{Y}$-positive and Pyronin $\mathrm{Y}$-negative cells (Figure 3B). Similar to the expression of PSF1 as influenced by cell density, Pyronin $\mathrm{Y}$-positive cells expressed higher levels of PSF1 mRNA than Pyronin $\mathrm{Y}$-negative cells (Figure 3C). Culture to confluence increased the number of Pyronin $\mathrm{Y}$-negative cells, but some Pyronin
$\mathrm{Y}$-positive cells were still present (Figure 3B). In confluent cultures, Pyronin $\mathrm{Y}$-positive cells also expressed higher levels of PSF1 mRNA than their negative counterparts (Figure 3C).

Next, the PSF1 promoter activity of vascular ECs was studied in an ex vivo model of angiogenesis using the aorta ring assay. On collagen type I gels, ECs in neovessels developing from the aorta ring of PSF1 promoter-EGFP mice expressed EGFP (Figure 3D). Matrigel plug assay was also used; when Matrigels containing VEGF and heparin were injected into PSF1 promoter-EGFP mice subcutaneously, CD31-positive neovessels derived from the skin vasculature were EGFP positive. This was seen despite the fact that CD31-negative EGFP-positive cells, possibly fibroblasts, also expressed EGFP (Figure 3E). In 
A

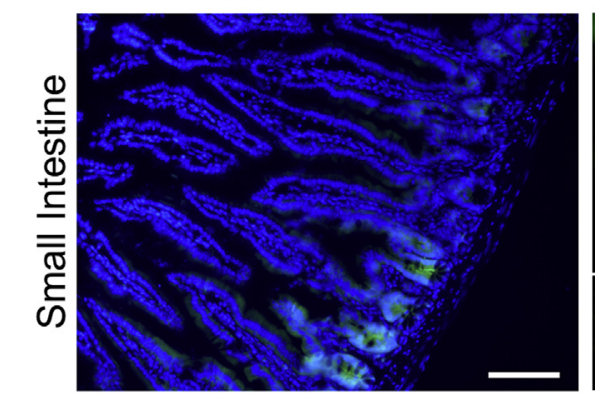

C

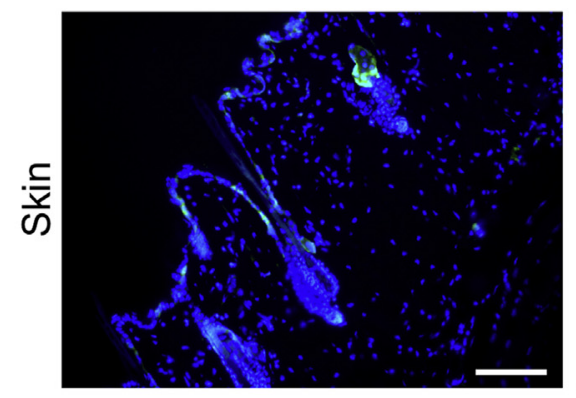

E

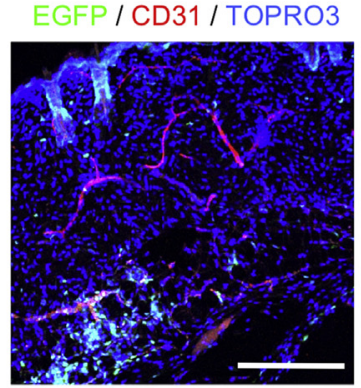

$\mathbf{F}$

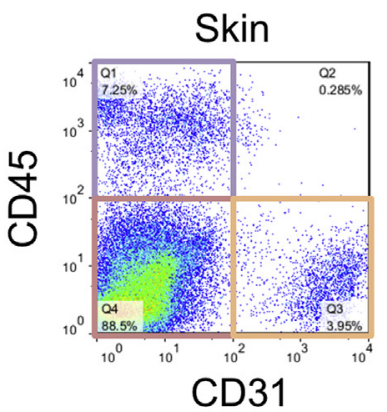

EGFP

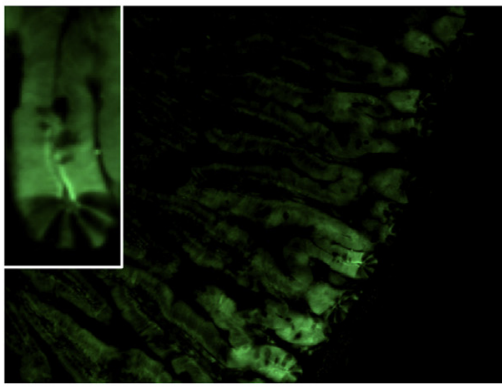

EGFP

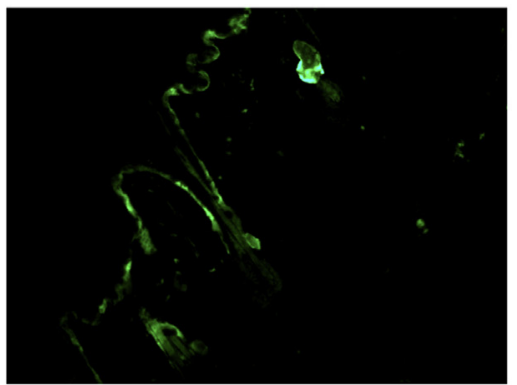

EGFP / CD31

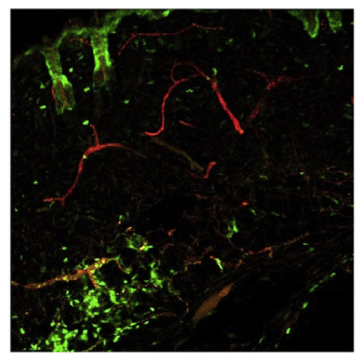

B

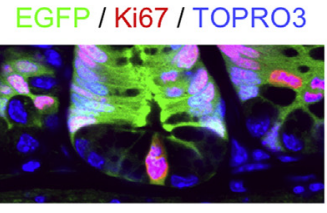

EGFP

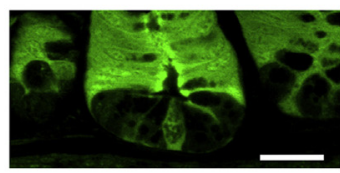

D EGFP / K5 / TOPRO3
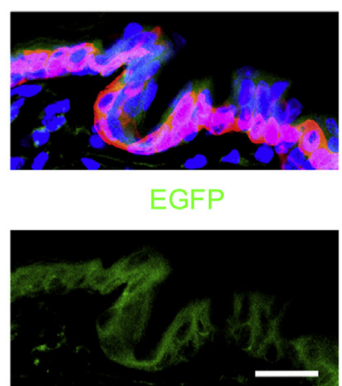

CD31

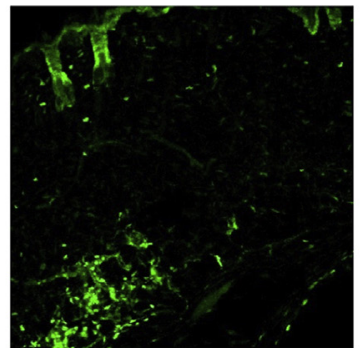

CD31-CD45-
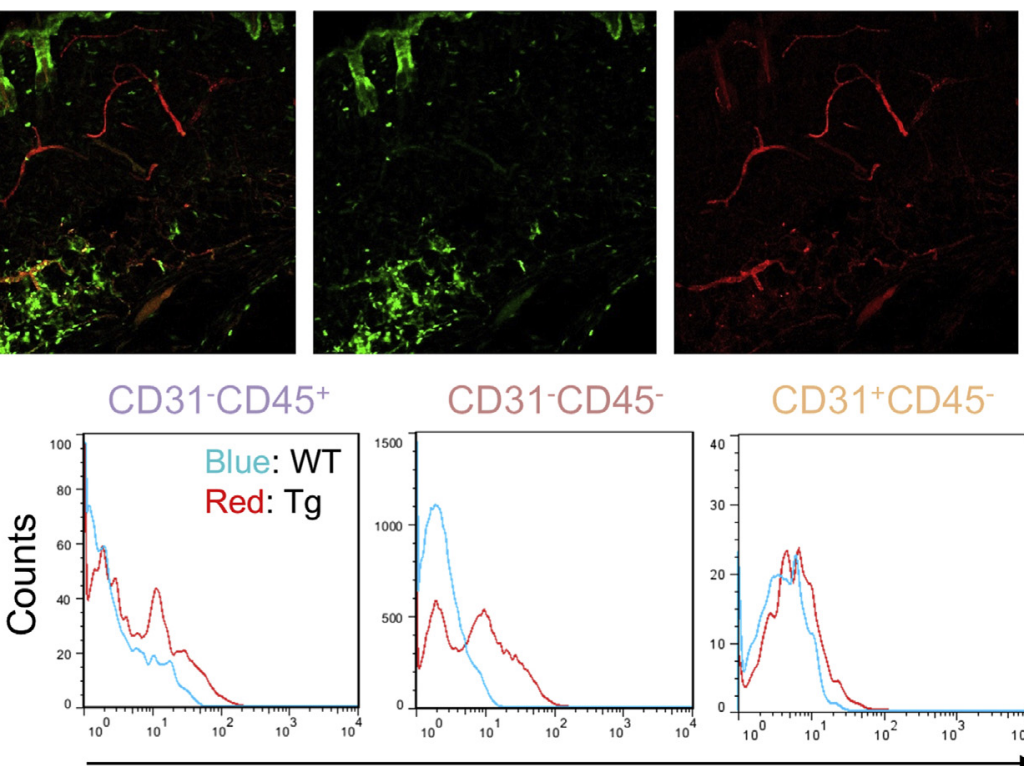

$\mathrm{CD} 31^{+} \mathrm{CD} 45$

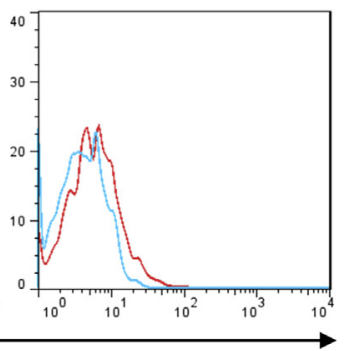

EGFP

Figure 2 PSF1 promoter activity in adult transgenic $(\mathrm{Tg})$ mice is silenced in most endothelial cells (ECs) A: Histologic analysis of EGFP-positive cells in the intestine from adult $\mathrm{Tg}$ mice. The white boxed area delineates the crypt region in intestinal tissue. On the basis of the localization, Paneth cells are EGFP negative. B: High-power view of the crypt region. $\mathrm{Ki}-67^{+}$proliferative cells express EGFP. C: Histologic analysis of EGFP-positive cells in skin from adult Tg mice. D: High-power view of epidermis. $\mathrm{K}^{+}$basal cells express EGFP. E: Immunofluorescence analysis of adult skin with CD31 (red) and EGFP. Nuclei are stained by T0-PRO-3 (blue). F: Flow cytometric analysis of skin tissue in wild-type (WT) or Tg mice. CD31- CD45 cells are leukocytes, $\mathrm{CD} 31^{+} \mathrm{CD} 45^{-}$cells are ECs, and $\mathrm{CD} 31^{-} \mathrm{CD} 45^{-}$cells contain epithelial cells and fibroblasts. Blue lines and red lines indicate cells from WT mice or Tg mice, respectively. Scale bars: $200 \mu \mathrm{m}$ (A); $20 \mu \mathrm{m}$ (B and D); $100 \mu \mathrm{m}$ (C); $250 \mu \mathrm{m}$ (E).

addition, it was investigated whether proliferating $\mathrm{EGFP}^{+}$ ECs can be detected in vivo using these PSF1 promoter-EGFP mice. First, brain tissues were stained on embryonic day 13.5. Some of the $\mathrm{CD} 31^{+}$vessels were stained for EGFP (Supplemental Figure S2A). Moreover,
$\mathrm{EGFP}^{+}$ECs were detected in neonatal retina (Supplemental Figure S2, B and C). Taken together, PSF1 promoter activity is up-regulated in ECs when angiogenesis is taking place, whereas dormant ECs in preexisting blood vessels express little or no PSF1. 
A

B
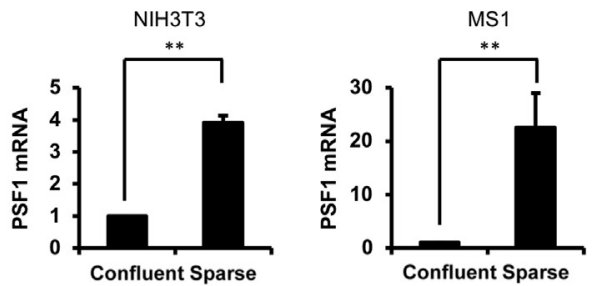

C
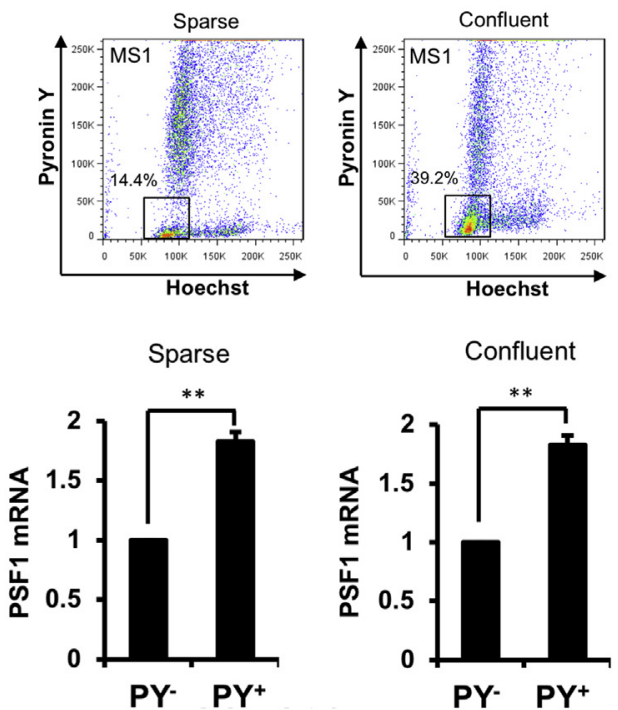

D
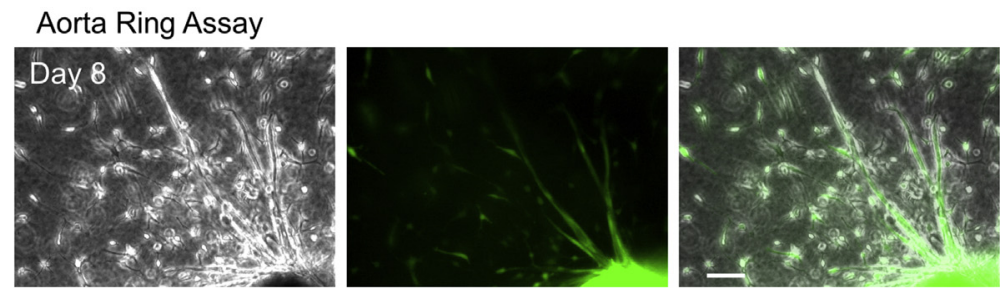

E

Matrigel Plug Assay
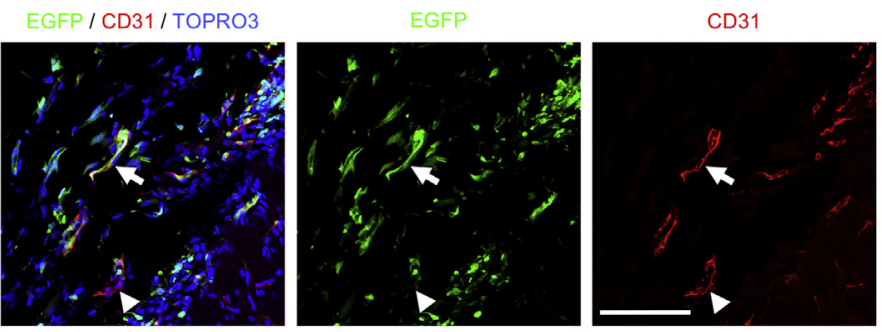

Figure 3 PSF1 promoter activity in cultured endothelial cells (ECS) and neovessels formed in the aorta ring assay and Matrigel plug assay. A: PSF1 mRNA expression of mouse fibroblast NIH3T3 cells or mouse endothelial MS1 cells in sparsely seeded or confluent conditions. B and C: Relation of PSF1 mRNA expression with cell cycle phase in ECs. B: Flow cytometric cell cycle analysis using Hoechst and Pyronin $Y$ staining in sparsely seeded or confluent MS1 cells. Black boxed area shows Pyronin $Y-$ negative and Hoechst-low cells. C: PSF1 mRNA expression of Pyronin Y (PY)-positive or PY-negative MS1 cells. D: Aorta ring assay from transgenic (Tg) mice. E: Matrigel plug assay using Tg mice. Section of Matrigel was stained with anti-CD31 antibody (red). Nuclei are stained by TO-PRO-3 (blue). Arrows indicate $\mathrm{EGFP}^{+}$vessels, and arrowheads indicate EGFP ${ }^{-}$ vessel. Data are expressed as means \pm SD (A and $\mathbf{C})$. $n=3$ (A and C). ${ }^{* *} P<0.01$. Scale bars: $75 \mu \mathrm{m}$ (D); $100 \mu \mathrm{m}(\mathrm{E})$.

\section{Visualization of Endothelial PSF1 Promoter Activity in Tumor Angiogenesis}

During tumor growth, neovascularization is induced by the sprouting and extension of ECs from the preexisting vasculature to supply nutrients and oxygen through new vessels. As previously described, preexisting blood vessels express little PSF1 promoter-driven EGFP (Figure 2, E and F). Proliferating ECs in the tumor derived from preexisting skin vasculature were visualized. B16 mouse melanoma cells were inoculated subcutaneously into mice, and after 3 days, tumor tissue was harvested together with skin. Interestingly, part of the skin vasculature near the tumor had become EGFP positive (Figure 4A). Moreover, EGFP-positive ECs extending from the skin vasculature toward the tumor cells were detected (Figure 4B). At a little far from tumor area, there are some EGFP-positive cells that seem to be hematopoietic cells and ECs. For the initiation of sprouting angiogenesis, many 
A Skin EGFP / CD31 / TOPRO3

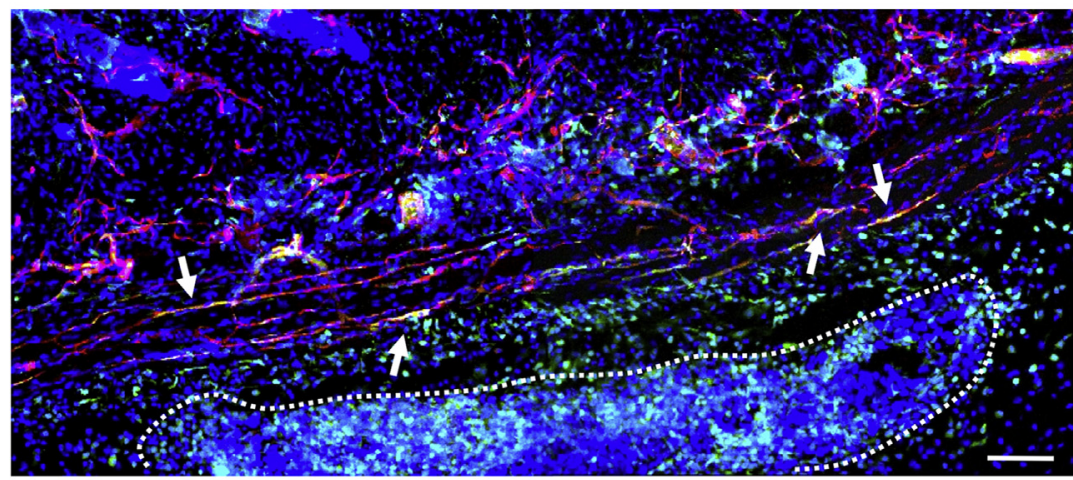

Tumor (B16)
B

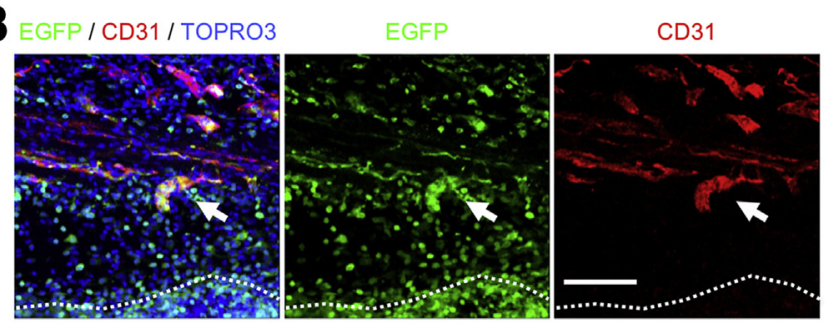

D

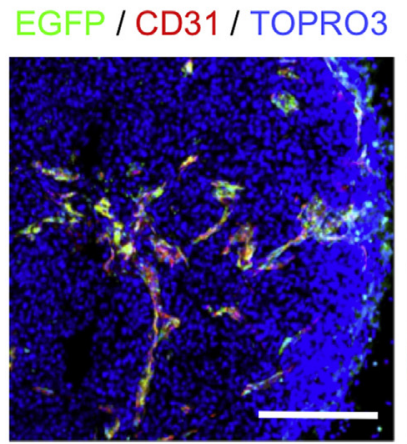

Day 7

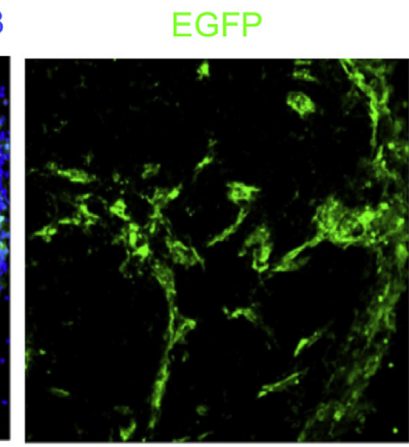

E

Day 3
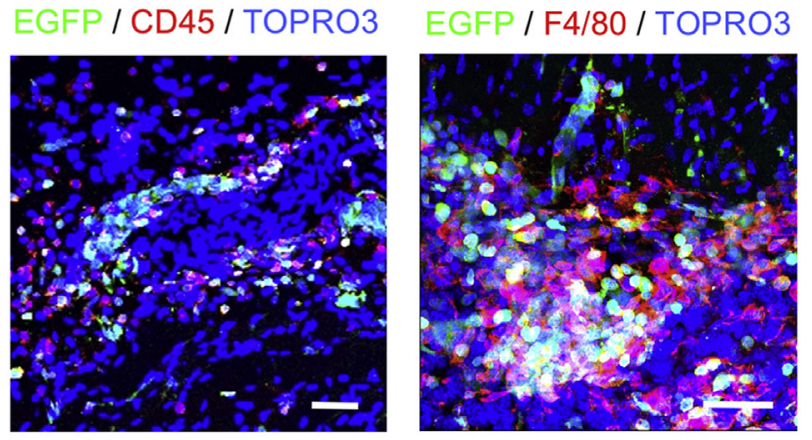

monocyte lineage cells and hematopoietic progenitor cells are recruited from preexisting blood vessels to the tumor; these cells have the ability to proliferate. Therefore, one possibility is that EGFP-positive and PSF1-activated hematopoietic cells
Day 3

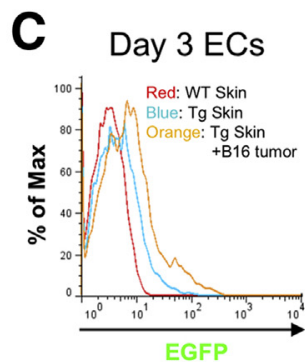

Figure 4 Initiation of tumor angiogenesis up-regulates PSF1 promoter activity in endothelial cells (ECS). A: Skin vasculature 3 days after B16 melanoma cell injection into the mouse. White dashed line indicates localization of tumor. Arrows indicate EGFPpositive ECs around the tumor. Two pieces of images were put together and edited to one piece. B: Sprouting new capillary from preexisting blood vessels around the tumor. White dashed line indicates localization of tumor. Arrows indicate budding ECs that express EGFP and CD31 (red). C: Flow cytometric analysis of endothelial PSF1 promoter activity in skin tissues around tumors 3 days after tumor cell inoculation. PSF1 promoter activity in ECs is increased in the skin vasculature, with B16 tumor inoculation (orange) relative to skin from wild type (WT; red) or transgenic ( $\mathrm{Tg}$; blue) mice in the steady state. D: PSF1 promoter activity of tumor vasculature 7 days after tumor cell inoculation. Section was stained with antiCD31 antibody (red). E: Immunostaining of hematopoietic (leukocyte, $\mathrm{CD}_{4} 5^{+}$; macrophage, $\mathrm{F} 4 / 80^{+}$; erythrocyte, Ter $119^{+}$) and $\alpha$ smooth muscle actin $(\alpha \text {-SMA })^{+}$smooth muscle cells (red) in the skin of $\mathrm{Tg}$ mice around the tumor tissue 3 days after tumor cell inoculation. Scale bars: $100 \mu \mathrm{m}(\mathbf{A}) ; 75$ $\mu \mathrm{m}$ (B); $250 \mu \mathrm{m}$ (D); $50 \mu \mathrm{m}$ (E). Max, maximum.
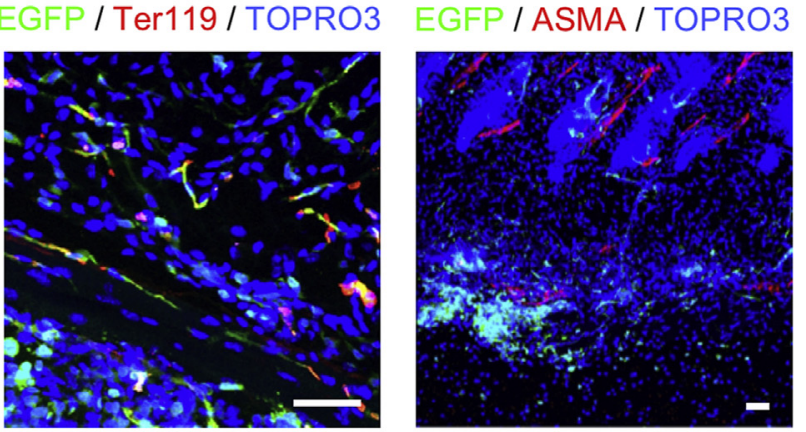

localize at a short distance from the tumor. Moreover, hematopoietic cells secrete angiogenic cytokines, such as VEGF and platelet-derived growth factor, which would affect endothelial cell growth in the locality. 
A
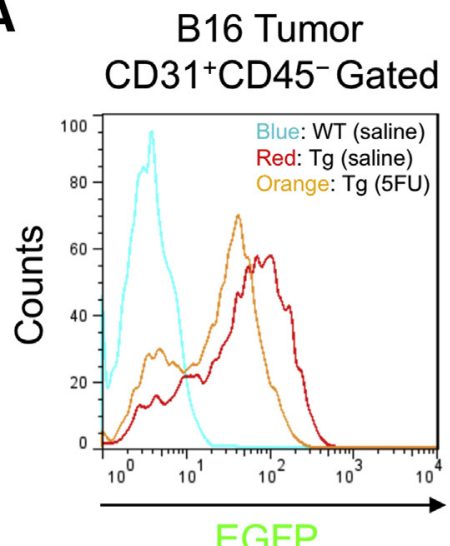

B
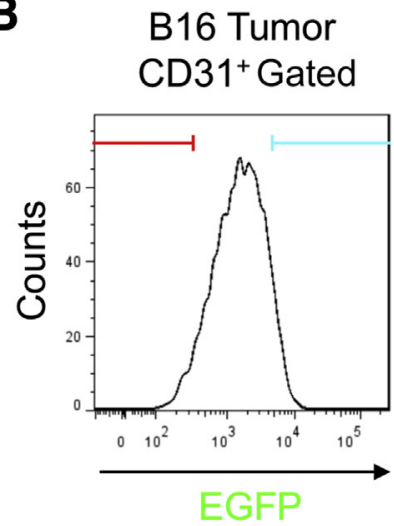

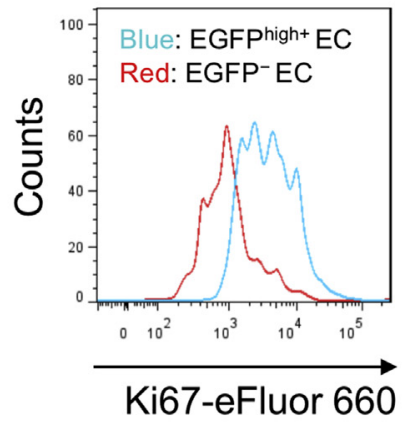

C

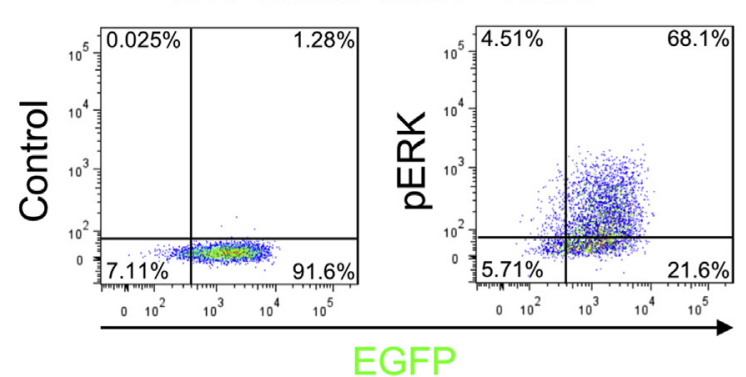

D
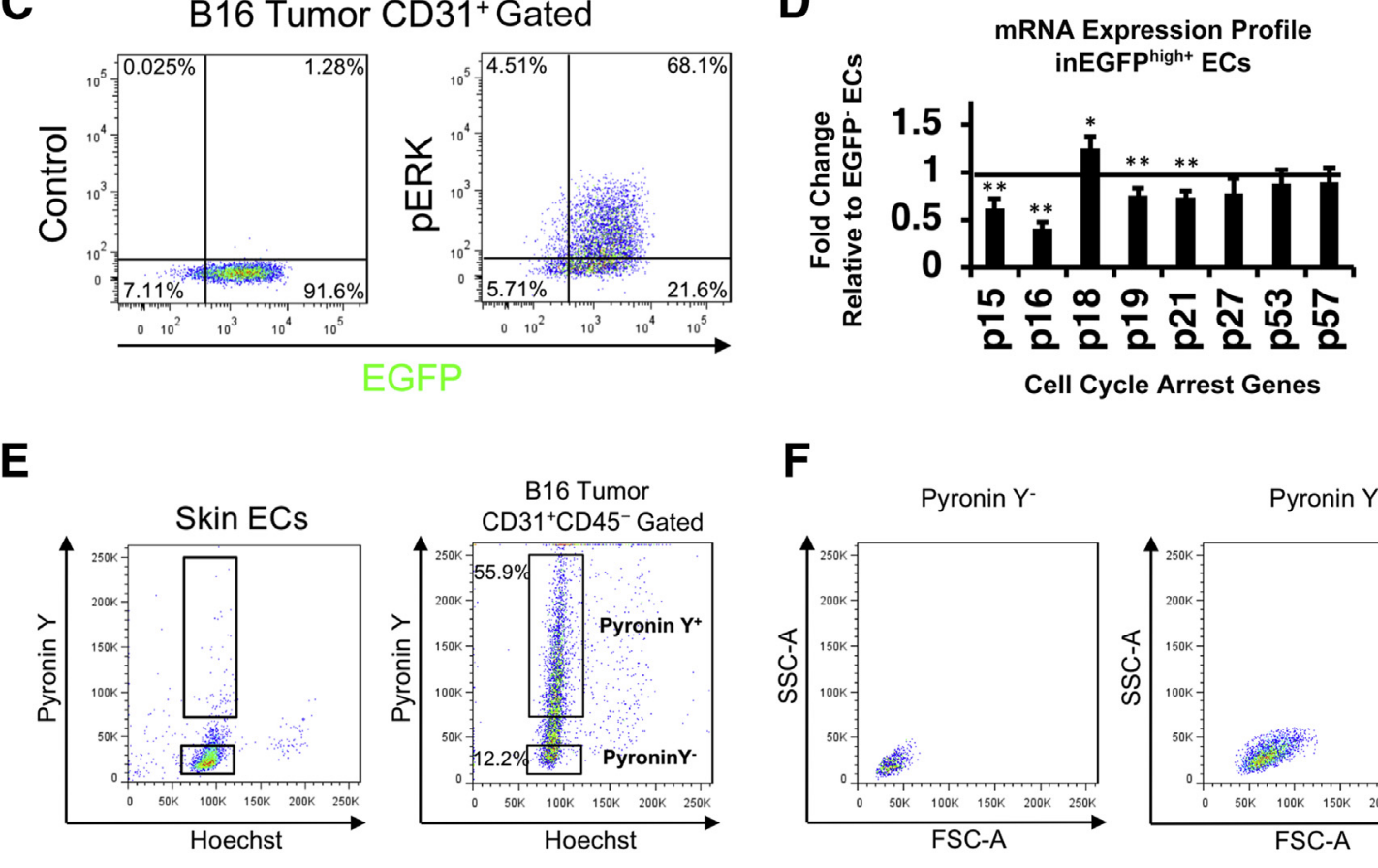

$\mathbf{F}$

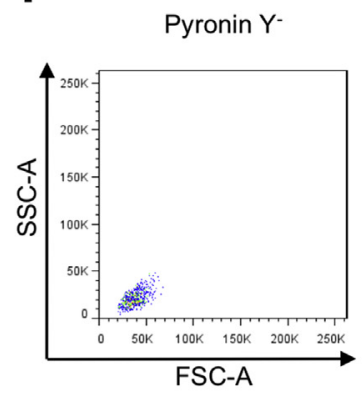

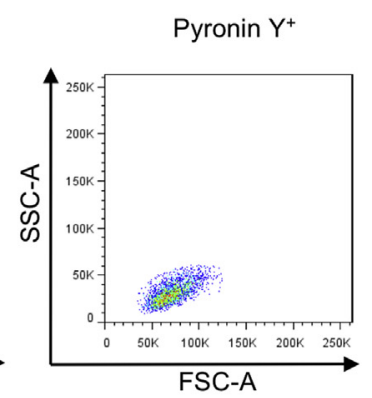

G
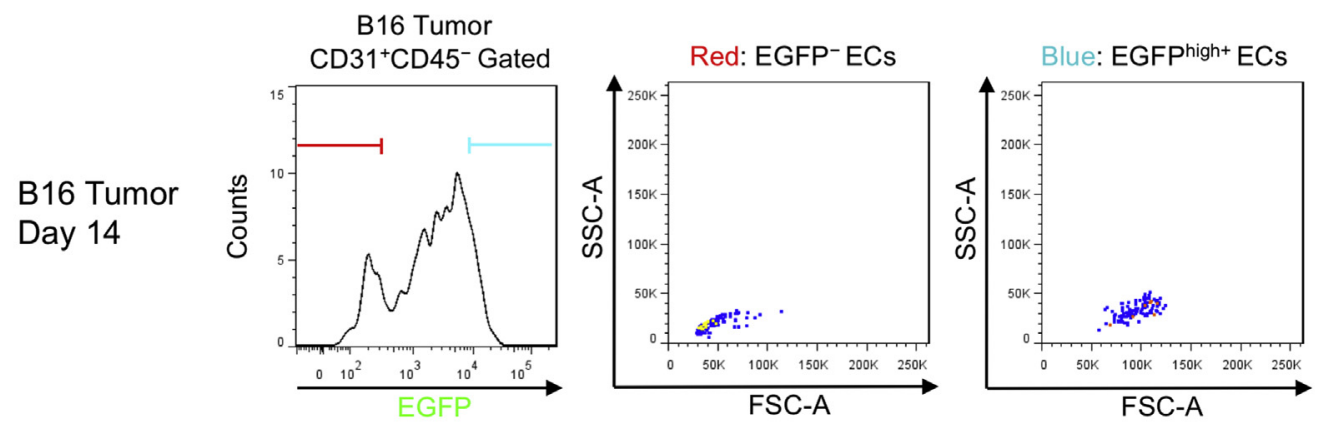

Figure 5 Proliferative capacity and cell cycle analysis of tumor endothelial cells (ECS) monitored by PSF1 promoter activity. A: Growth inhibition of EGFPhigh+ ECs by 5 -fluorouracil (5-FU) analyzed by flow cytometry. B: Flow cytometric analysis of Ki-67 positivity in EGFPhigh+ and EGFP- ECs from tumors generated by s.c. inoculation of B16 melanoma cells. C: Detection of extracellular signal-regulated kinase (ERK) phosphorylation in tumor ECs from transgenic (Tg) mice. $\mathrm{EGFP}^{\text {high+ }}$ ECs showed higher ERK phosphorylation (pERK) levels compared with EGFP- ECs. D: Profiling of cell cycle arrest-related gene expression in EGFPhigh+ ECs from B16 tumors. The level of mRNA expression in EGFP ${ }^{-}$ECs from tumor was set as unity. E: Hoechst and Pyronin Y staining of ECs from the skin or B16 tumor of wild-type (WT) mice. Black boxed areas indicate Pyronin $\mathrm{Y}^{+}$or Pyronin $\mathrm{Y}^{-}$ECs within Hoechst-low cells, respectively. F: Forward and side scatter (FSC and SSC, respectively) plots of B16 tumor EC fraction divided by Pyronin positivity, as indicated in E. G: Forward and side scatter plots of EGFP-negative or highly positive B16 tumor EC fractions in Tg mice. EGFP positivity was determined as indicated by red or blue bars in the left panel. Middle and right panels indicate EGFP negative or high positive ECs. Data are expressed as means \pm SD (D). $n=3$ (D). ${ }^{*} P<0.05,{ }^{*} P<0.01$ EGFP negative versus high positive ECs. 
A

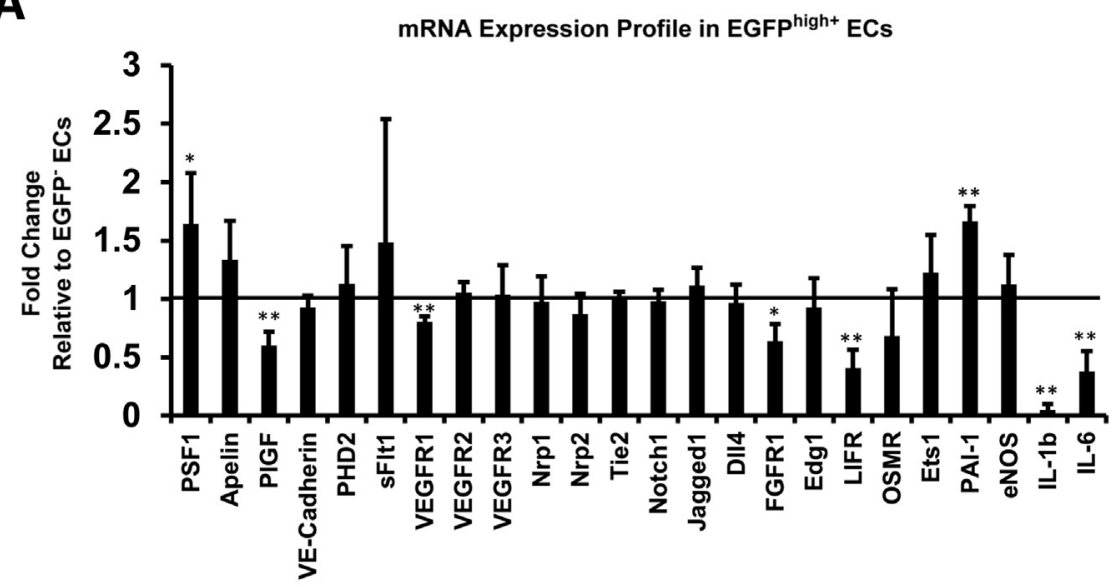

B

B16 Tumor Day 14

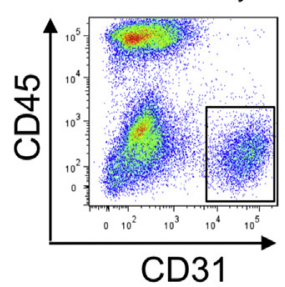

Tie2
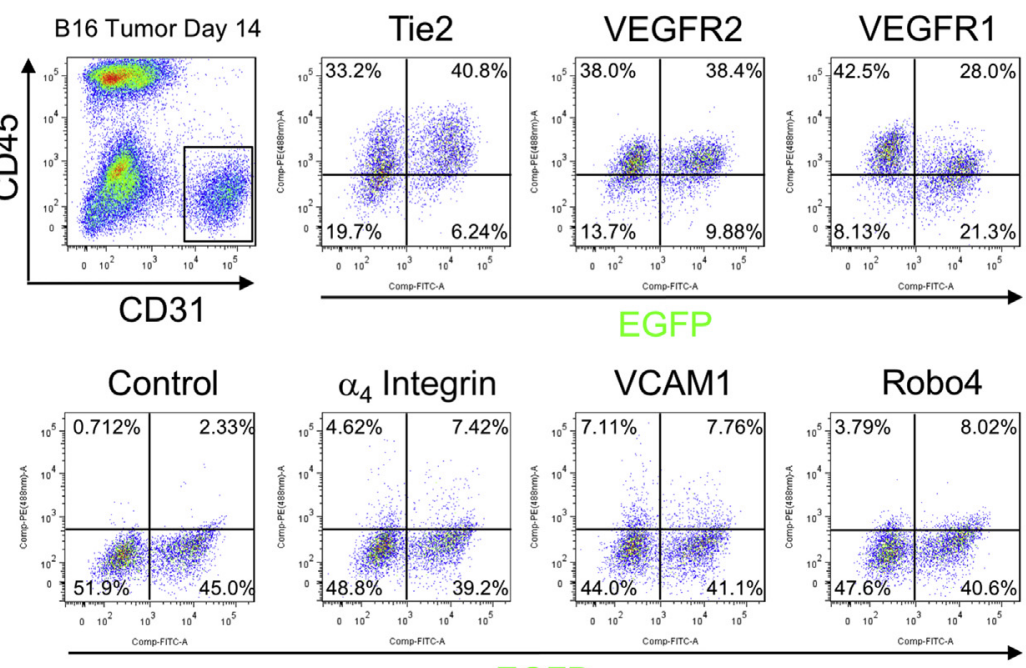

EGFP

C
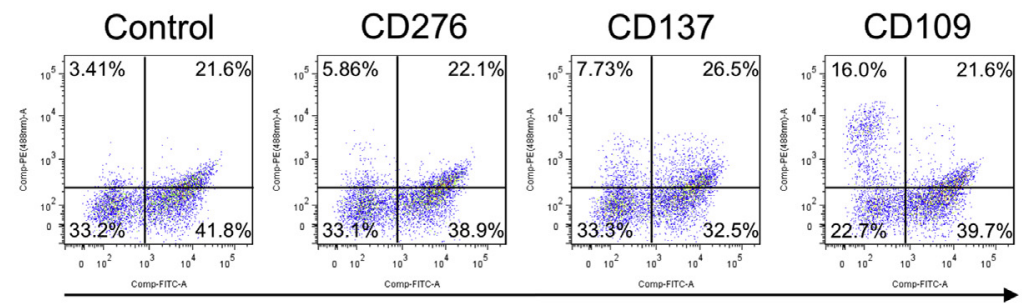

Figure 6 Identification of angiogenesisrelated factor expression in tumor endothelial cells (ECS) depending on PSF1 promoter activity. A: Profiles of angiogenesis-related mRNA expression in EGFPhigh+ ECs from B16 tumor developing in transgenic $(\mathrm{Tg})$ mice. The level of mRNA expression in EGFP ${ }^{-}$ECs from tumor was set as unity. B: Cell surface molecule expression on tumor ECs by flow cytometric analysis focusing on tyrosine kinase receptors (top panels) and molecules associating with endothelial adhesion and migration (bottom panels) ( $y$ axis). Expression levels compared with PSF1 promoter activity ( $x$ axis). C: Flow cytometric analysis of known tumor endothelial-specific markers as indicated in tumor ECs from $\mathrm{Tg}$ mice. Data are expressed as means \pm SD (A). $n=3(\mathbf{A})$. ${ }^{*} P<0.05,{ }^{*} P<0.01$ EGFP negative and high positive ECs. Edg, ; eNOS, endothelial nitric oxide synthase; Ets, sphingosine-1-phosphate receptor; FGFR, fibroblast growth factor receptor; LIFR, leukemia inhibitory factor receptor; Nrp, neuropilin; OSMR, oncostatin $M$ receptor; PAI, plasminogen activator inhibitor; PHD, prolyl hydroxylase; PIGF, placenta growth factor; sFlt, soluble Flt; Tie, tyrosine kinase with immunoglobulin-like and EGF-like domain; VCAM, vascular cell adhesion molecule; VEGFR, vascular endothelial growth factor receptor.

EGFP

To confirm that cells double labelled by CD31 and EGFP were ECs, flow cytometry was used to show that $\mathrm{CD} 31^{+} \mathrm{CD} 45^{-}$gated ECs in tumors express a higher level of EGFP than those in the skin in the steady state (Figure 4C). Seven days after tumor cell inoculation, most CD $31^{+} \mathrm{ECs}$ in the tumor expressed EGFP (Figure 4D). Part of the round cell population expressing the leukocyte marker CD45 or the monocyte marker F4/80 expressed EGFP (Figure 4E). However, Ter119-positive erythrocytes and $\alpha$-smooth muscle actin-positive mesenchymal cells expressed little
EGFP (Figure 4E). These results suggest that $\mathrm{CD} 31^{+} \mathrm{ECs}$ and some hematopoietic cells expressed EGFP in the skin near the tumor. Similar results were also obtained using the mouse Lewis lung carcinoma cell line LLC as the s.c. tumor instead of B16 cells (Supplemental Figure S3, A and B). One difference relative to the B16 tumor model was that LLC tumors contained abundant EGFP-positive hematopoietic cells (Supplemental Figure S3, C-E), suggesting that visualization of $\mathrm{EGFP}^{+} \mathrm{ECs}$ in the tumor microenvironment is more readily achieved in the B16 model. 
A

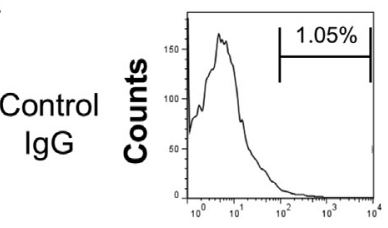

B

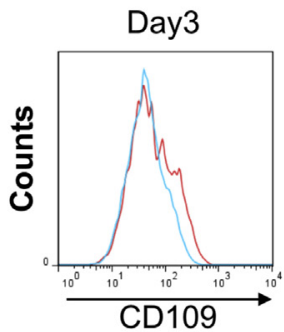

D
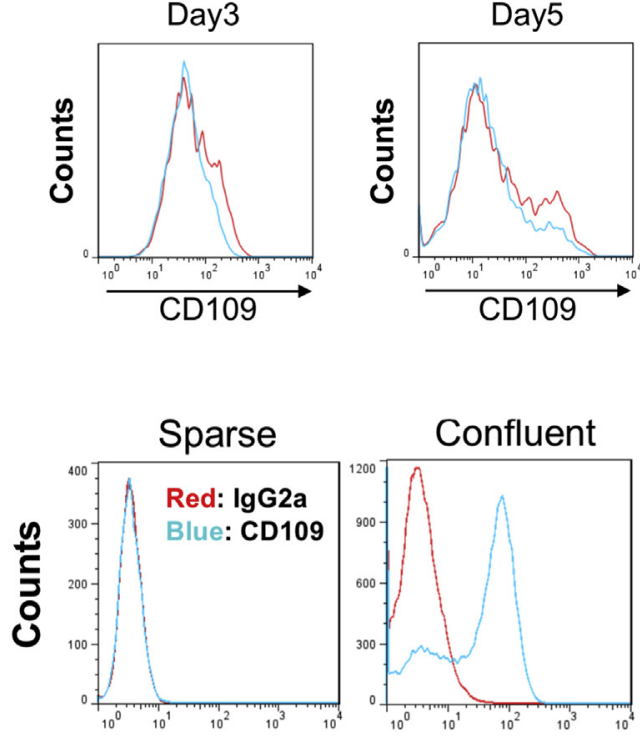

$\mathbf{E}$

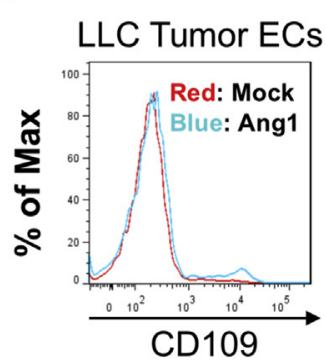

Day5
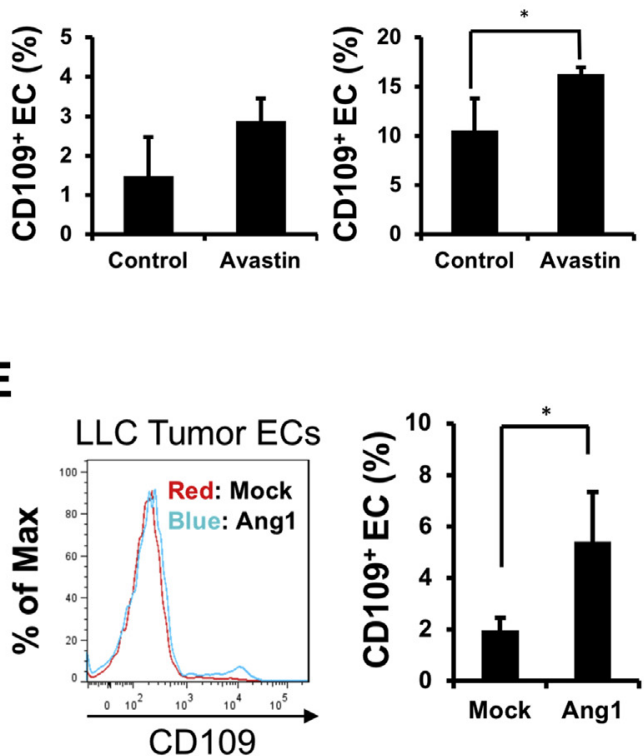

$\mathbf{F}$
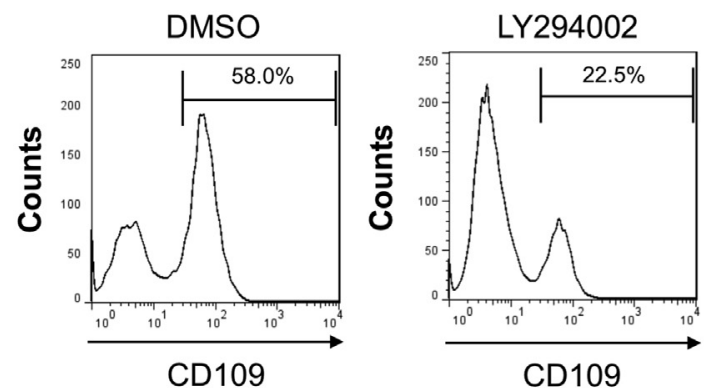

Figure $7 \mathrm{CD} 109$ is a vascular stabilization marker and is up-regulated by phosphatidylinositol 3-kinase (PI3K) signaling. A: Flow cytometric analysis showing changes of CD109 expression in B16 tumor endothelial cells (ECs) after 5-fluorouracil (5-FU) treatment. B: Flow cytometric analysis showing the changes of CD109 expression in ECs after one injection of bevacizumab. C: Quantitative evaluation of percentage of CD109+ ECs observed in B. D: Differences in CD109 expression depending on cell density in MS1 cells. E: Involvement of angiopoietin-1 (Ang1) in the expression of endothelial CD109 in tumor. Quantitative evaluation of CD109 expression observed in the left panel is shown on the right panel. Ang1 significantly induces CD109 expression in ECs. F: Involvement of the PI3K pathway CD109 expression by MS1 cells. The PI3K inhibitor LY294002 suppresses CD109 expression on confluent MS1 cells. Data are expressed as means \pm SD (C and $\mathbf{E}) . n=3(\mathbf{A}, \mathbf{C}$, and $\mathbf{E})$. ${ }^{*} P<0.05$. DMS0, dimethyl sulfoxide; Max, maximum.

\section{PSF1 Promoter-Active ECs in Tumors Have High Proliferative Activity}

PSF1 promoter activity in ECs is up-regulated in the tumor. The correlation of PSF1 promoter activity with cell growth in tumor ECs was studied next. First, the DNA synthesis inhibitor 5-FU was used during tumor development. As expected, 5-FU treatment inhibited the growth of ECs with high PSF1 promoter activity (EGFP ${ }^{\text {high+ }}$ ECs) (Figure 5A). The relevance of expression of the cell growth marker Ki-67 and the status of extracellular signal-regulated kinase phosphorylation in such EGFP ${ }^{\text {high }+}$ ECs was also studied. ${ }^{26}$ $\mathrm{EGFP}^{-}$or EGFP ${ }^{\text {high+ }}$ ECs were isolated from the tumor, and it was found that the latter expressed higher levels of Ki-67 and contained more phosphorylated extracellular signal-regulated kinase than $\mathrm{EGFP}^{-}$ECs (Figure 5, B and C). These data strongly suggest that PSF1 promoter activity correlates well with cell growth.

Next, the relationship between the expression of cell cycle arrest genes (p15, p16, p18, p19, p21, p27, p53, and 
p57) and PSF1 promoter activity was examined. This analysis revealed that most cell cycle arrest gene expression was lower in $\mathrm{EGFP}^{\text {high+ }}$ ECs than in $\mathrm{EGFP}^{-}$ECs (Figure 5D), suggesting that $\mathrm{EGFP}^{\text {high }+}$ ECs enter cell cycle progression. It is well known that migrating cells and dividing cells have a specific different morphology. Most obviously, proliferating cells contain many intracellular compartments necessary for the active synthesis of RNA and DNA. ${ }^{13}$ Therefore, EC morphology was characterized in cells with or without PSF1 promoter activity. Using both the Pyronin Y and Hoechst cell staining methods, it was found that ECs in normal skin synthesized little RNA, whereas there is vigorous RNA synthesis in tumor ECs (Figure 5E). Next, the morphological complexity of the intracellular compartment was studied by flow cytometry. Interestingly, those ECs with higher capacity RNA synthesis were larger (as determined by forward scatter) and had greater intracellular complexity (as determined by side scatter) than cells with a low RNA synthesis capacity (Figure 5F). Similarly, EGFP ${ }^{\text {high }+}$ ECs in the tumor were larger and had greater intracellular complexity than EGFP ${ }^{-}$ ECs (Figure 5G). These data indicate that PSF1 promoter activity in tumor ECs correlates with cell growth, suggesting that PSF1 promoter-EGFP mice can be used to visualize proliferating ECs by their EGFP expression.

\section{Classification of Quiescent or Proliferating ECs in the Tumor as Monitored by PSF1 Promoter Activity}

PSF1 promoter activity can be used to visualize proliferating ECs in tumors in vivo. To determine specific gene expression in cells differing by the intensity of their PSF1 promoter activity, tumor ECs were sorted and the expression of genes related to vascular formation was assessed using real-time PCR. EGFP ${ }^{\text {high }+}$ ECs had only an approximately 1.6-fold higher expression of PSF1 mRNA. This may have been influenced by the time lag between EGFP protein production and degradation. Relative to $\mathrm{EGFP}^{-} \mathrm{ECs}^{\mathrm{E}} \mathrm{EGFP}^{\text {high }+} \mathrm{ECs}$ strongly expressed plasminogen activator inhibitor-1 (Figure 6A). Conversely, mRNA expression of PlGF, VEGFR1, FGFR1, LIFR, IL1b, and IL6 was lower in EGFP $^{\text {high }+}$ ECs. Previous reports have noted that PlGFVEGFR1 signaling induces vascular stabilization. ${ }^{27}$ In structurally stable blood vessels, ECs are quiescent and possess the phalanx phenotype. ${ }^{3}$ Therefore, we hypothesized that $\mathrm{EGFP}^{-}$ECs would have the phalanx phenotype. Indeed, PIGF-VEGFR1 signaling through an autocrine loop did tend to be slightly activated in EGFP ${ }^{-}$ECs; however, no changes were observed in phalanx phenotype gene signatures, such as VE-cadherin, prolyl hydroxylase 2 (PHD2), and soluble VEGFR $1 .{ }^{3}$ Therefore, cell growth activity in phalanx cells needs further investigation.

Next, cell surface protein expression was quantified. No change was observed in VEGFR2, consistent with its mRNA level (Figure 6B). In contrast, despite a lack of difference of VEGFR1 mRNA expression, VEGFR1 protein expression was lower in $\mathrm{EGFP}^{\text {high+ }}$ ECs than in $\mathrm{EGFP}^{-}$ cells. It is possible that extracellular domain of VEGFR1 was shed by a matrix metalloproteinase when angiogenic stimuli affect ECs. ${ }^{28}$

a4 Integrin, vascular cell adhesion molecule 1, and Robo4 are up-regulated in ECs during angiogenesis. ${ }^{29,30}$ However, no significant differences in these proteins in EGFP $^{-}$or EGFP ${ }^{\text {high+ }}$ ECs were observed (Figure 6B).

It has been reported that gene expression profiles are different in ECs under conditions of pathologic or physiological angiogenesis. ${ }^{1}$ The cell surface proteins CD276, CD137, and CD109 have been detected in tumor ECs only. Herein, it was assessed whether these molecules are present only on tumor ECs. There was little or no CD276 or CD137 expression on either EGFP $^{-}$or EGFP ${ }^{\text {high+ }}{ }^{\text {ECs (Figure 6C). }}$ However, the glycosylphosphatidylinositol anchor protein CD109 was expressed by a subpopulation of EGFP ${ }^{-}$ECs (Figure 6C). Analyzing the LLC tumor model instead of B16 yielded similar results (Supplemental Figure S4). On the other hand, CD109 mRNA expression was not markedly different between $\mathrm{EGFP}^{-}$and $\mathrm{EGFP}^{\text {high+ }}{ }^{\mathrm{ECC}}$ in LLC and B16 tumors (Supplemental Figure S5, A and B). This may reflect the small population of CD109-positive cells among the EGFP $^{-}$ECs. In normal skin, most ECs are in a dormant condition, and only one-fifth express CD109 (Supplemental Figure S5C). This suggests that CD109 is uniquely expressed in quiescent ECs in tumors and is related to vascular stabilization.

\section{Vascular Stabilization Induces Endothelial CD109 Expression}

Nonproliferative ECs (EGFP ${ }^{-}$ECs) strongly expressed VEGFR1 and CD109 (Figure 6). We hypothesized that VEGFR1 and CD109 expression was induced by vascular stabilization in the tumor microenvironment. To test this, two models of vascular stabilization using 5-FU or the anti-VEGF monoclonal antibody bevacizumab were used. 5-FU was used in the same way as in Figure 5A. As the number of EGFP $^{-}$ECs increased, the fraction of CD109-positive cells also significantly increased (Figure 7A). Although bevacizumab inhibits VEGF-dependent endothelial cell growth and migration, it can also induce vessel maturation, depending on time of exposure. To evaluate whether increased CD109 expression occurred in the so-called normalization window, a previously validated method ${ }^{22}$ was used. Bevacizumab was injected once into human colorectal adenocarcinoma HT29-bearing mice. With time, vessel density decreased, but on day 5 after bevacizumab injection, pericyte-covered mature vessels were detected. At this time, functional vessels increased and hypoxic regions significantly decreased. However, on day 8 after bevacizumab injection, hypoxic regions increased again. Because of this, we had previously concluded that normalization of tumor vessels was induced from days 3 to 5 after bevacizumab injection in our model. ${ }^{22}$ Accordingly, as 
expected, enhanced CD109 expression was detected on days 3 and 5 after bevacizumab injection (Figure 7, B and C).

Next, in vitro culture experiments were performed because it is known that cell density affects cell proliferation. Sparse cell seeding induces proliferation and migration, whereas cell-cell contact in confluent cultures suppresses proliferation and migration and induces cell cycle arrest. Interestingly, MS1 cells express little CD109 in sparsely seeded cultures, but it was induced at confluence (Figure 7D).

Previously, we have shown that angiopoietin-1 (Ang1)/ Tie2 signaling enhances EC-EC cell adhesion, resulting in structurally stable blood vessels in which mural cells cover the ECs. ${ }^{31}$ In addition, we previously reported that overexpression of Ang1 in tumor cells induced intratumoral blood vessel maturation, whereby mural cells covered ECs and inhibited tumor growth more than in tumors derived by inoculation with parental tumor cells. ${ }^{31}$ Herein, the same Ang1-overexpressing LLC tumor model was used. In these tumors, the number of CD109-positive ECs was approximately twice that seen in parental LLC tumors (Figure 7E). PI3K-Akt signaling is a major vascular stabilization pathway under Tie2 activation with Ang $1 .{ }^{32}$ Inclusion of the PI3K inhibitor LY294002 in MS1 cultures suppressed CD109 induction, even in confluent cells (Figure 7F). These results suggest that CD109 expression in tumor ECs was induced in parallel with vascular stabilization via the PI3K-Akt pathway.

It has been suggested that pericyte coverage is involved in the process of vascular maturation and that ECs are rendered dormant after pericyte coverage. Therefore, finally, the relationship between pericyte coverage and CD109 expression and PSF1 promoter activity was analyzed. Endothelial CD109 expression was tested by immunostaining, but was found to be technically challenging. Instead, the relationship between PSF1 promoter activity and pericyte coverage was assessed. The results showed that some EGFP-negative/low vessels are present in pericyte-covered vessels but others are in vessels that are not covered (Supplemental Figure S6). Moreover, some highly EGFP-positive vessels were covered with pericytes (Supplemental Figure S6). Therefore, these findings suggest that pericyte coverage is, in fact, not correlated with tumor vasculature dormancy.

\section{Discussion}

Normalization of the tumor vasculature is an effective method for improving drug delivery into tumors. However, a major clinical problem with this treatment is how to recognize the vascular normalization window for optimal timing of drug delivery. ${ }^{33}$ To approach this issue, the identification of specific markers would be extremely useful. ${ }^{2,3,34}$ In the present study, we distinguish between proangiogenic proliferating ECs and quiescent ECs in tumors on the basis of their PSF1 promoter activity. CD109 was highly expressed in dormant
ECs and could be used to detect normalized blood vessels, thus allowing identification of the window of opportunity for optimal delivery of chemotherapeutics.

Several methods for detecting proliferating cells can be applied, such as bromodeoxyuridine incorporation, proliferating cell nuclear antigen staining, Ki-67 staining, or Pyronin Y/Hoechst staining. These methods take time to detect proliferating cells, and only bromodeoxyuridine and Pyronin Y/Hoechst staining can be used to detect cell cycling in living cells. Moreover, it is unclear whether any of these methods reflects the genuine in vivo condition of living cells. To overcome this potential difficulty, the Fucci system has been developed. ${ }^{25}$ However, the Fucci system can identify $G_{1}, S$, $\mathrm{G}_{2}$, and $\mathrm{M}$ phases but cannot distinguish between $\mathrm{G}_{1}$ and $\mathrm{G}_{0}$. Our system monitoring PSF1 promoter activity resolves this problem. PSF1 promoter-EGFP ${ }^{-}$ECs had lower levels of Ki-67 positivity than PSF1 promoter-EGFP ${ }^{\text {high }+}$ ECs and were dormant in the tumor (Figure 5). Therefore, PSF1 promoter activity is especially suitable for detection of cell cycle status in living dormant ECs.

VEGFR1 is known as a VEGF decoy receptor and is involved in antiangiogenesis. ${ }^{35}$ In addition, sVEGFR1 regulates sprouting at the angiogenic front in a concentrationdependent manner. ${ }^{36}$ The consensus is that VEGFR1 functions as a decoy receptor by trapping VEGF and, thus, regulates angiogenesis. Consistent with this, inhibition of PlGF/ VEGFR1 signaling suppressed tumor growth without affecting healthy vessels. ${ }^{27}$ Interestingly, in our model, VEGFR1 expression is down-regulated in PSF1 promoter-EGFP high+ ECs. These data suggest that PSF1 promoter-EGFP ${ }^{\text {high }}$ ECs may be highly sensitive to VEGF stimulation.

It is widely accepted that ECs proliferating during angiogenesis are stalk cells expressing specific markers. Previous reports have shown that the transforming growth factor family cell surface receptor CD105 (endoglin) and the transcription factor SRY-related HMG-box transcription factor (Sox)17 are proangiogenic endothelial markers. ${ }^{3,37}$ However, ECs in preexisting blood vessels also express CD105, and arterial ECs stably express Sox $17 .{ }^{38}$ Therefore, such markers alone cannot be used to distinguish between proangiogenic and dormant ECs, although it has been reported that more ECs with high levels of Sox17 and VEGFR2 are in $S / G_{2} / M$ phase in tumors, relative to Sox17-low ECs. In our experiments, PSF1 promoter activity did not correlate with the amount of VEGFR2 expressed by the cells. This suggests that Sox 17 is expressed by ECs at the onset of sprouting angiogenesis and does not distinguish between stalk and phalanx cells.

Interactions between tip and stalk cells during sprouting angiogenesis have been well studied at the molecular level, showing that Notch1-Dl14 and Jagged1 expression and regulation is involved in this process. It has been reported that disruption of Notch signaling induces excessive generation of tip cells. ${ }^{39-43}$ However, in this study using PSF1 promoter activity, the level of expression of these genes was only marginally changed, suggesting that the 
EGFP-negative EC population contains not only phalanx cells but also nonproliferative stalk cells. However, further analysis is required to determine how to distinguish between tip, stalk, and phalanx cells, according to their proliferative status.

Seaman et $\mathrm{al}^{7}$ have reported that tumor ECs express 13 specific genes, of which CD109, CD137, and CD276 were tested at the protein level and only CD109 was identified as different, depending on PSF1 promoter activity in tumor ECs. Tumor-specific gene expression was expected in proliferating ECs, but CD109 was also present on nonproliferating ECs.

Previous reports have shown that the ectodomain of CD109 is cleaved, and that soluble CD109 inhibits transforming growth factor- $\beta$ signaling through direct binding to transforming growth factor- $\beta .{ }^{44}$ It is possible that inhibition of transforming growth factor- $\beta$ signaling promotes tumor vascular formation because vascular maturation is perturbed. This suggests that intact CD109 expression on the cell surface of ECs reflects endothelial maturation and dormancy.

Ang1 overexpression in tumors induced CD109 and the $\mathrm{PI} 3 \mathrm{~K}$ signaling pathway is involved in this process, strongly suggesting that CD109 is a vascular stabilization marker. Although Nolan et $\mathrm{al}^{5}$ proposed that ECs are heterogeneous, depending on the organ of origin, it is likely that CD109 expression is a common phenotype, not depending on physiological or pathologic conditions.

New therapeutic strategies to improve drug delivery for more effective antitumor therapy are highly desirable. As previously alluded to, one approach to this is the induction of vascular stabilization in the tumor. This would reduce hypoxia in the tumor and inhibit progression of tumor malignancy. Therefore, monitoring CD109 expression in tumor vessels may be an effective screening method to recognize the normalization window and determine optimal timing for treatment with anticancer drugs.

\section{Acknowledgments}

We thank Noriko Fujimoto, Keisho Fukuhara, and Yoko Mori for technical assistance.

\section{Supplemental Data}

Supplemental material for this article can be found at https://doi.org/10.1016/j.ajpath.2018.01.015.

\section{References}

1. Chung AS, Lee J, Ferrara N: Targeting the tumour vasculature: insights from physiological angiogenesis. Nat Rev Cancer 2010, 10: $505-514$

2. Jain RK: Antiangiogenesis strategies revisited: from starving tumors to alleviating hypoxia. Cancer Cell 2014, 26:605-622

3. Mazzone M, Dettori D, de Oliveira RL, Loges S, Schmidt T, Jonckx B, Tian YM, Lanahan AA, Pollard P, de Almodovar CR, De Smet F,
Vinckier S, Aragonés J, Debackere K, Luttun A, Wyns S, Jordan B, Pisacane A, Gallez B, Lampugnani MG, Dejana E, Simons M, Ratcliffe P, Maxwell P, Carmeliet P: Heterozygous deficiency of PHD2 restores tumor oxygenation and inhibits metastasis via endothelial normalization. Cell 2009, 136:839-851

4. Gerhardt H, Golding M, Fruttiger M, Ruhrberg C, Lundkvist A, Abramsson A, Jeltsch M, Mitchell C, Alitalo K, Shima D, Betsholtz C: VEGF guides angiogenic sprouting utilizing endothelial tip cell filopodia. J Cell Biol 2003, 161:1163-1177

5. Nolan DJ, Ginsberg M, Israely E, Palikuqi B, Poulos MG, James D, Ding BS, Schachterle W, Liu Y, Rosenwaks Z, Butler JM, Xiang J, Rafii A, Shido K, Rabbany SY, Elemento O, Rafii S: Molecular signatures of tissue-specific microvascular endothelial cell heterogeneity in organ maintenance and regeneration. Dev Cell 2013, 26:204-219

6. Adams RH, Alitalo K: Molecular regulation of angiogenesis and lymphangiogenesis. Nat Rev Mol Cell Biol 2007, 8:464-478

7. Seaman S, Stevens J, Yang MY, Logsdon D, Graff-Cherry C, St Croix B: Genes that distinguish physiological and pathological angiogenesis. Cancer Cell 2007, 11:539-554

8. Ueno M, Itoh M, Kong L, Sugihara K, Asano M, Takakura N: PSF1 is essential for early embryogenesis in mice. Mol Cell Biol 2005, 25: $10528-10532$

9. Ueno M, Itoh M, Sugihara K, Asano M, Takakura N: Both alleles of PSF1 are required for maintenance of pool size of immature hematopoietic cells and acute bone marrow regeneration. Blood 2009, 113:555-562

10. Nagahama $\mathrm{Y}$, Ueno M, Miyamoto S, Morii E, Minami T, Mochizuki N, Saya H, Takakura N: PSF1, a DNA replication factor expressed widely in stem and progenitor cells, drives tumorigenic and metastatic properties. Cancer Res 2010, 70:1215-1224

11. Kidoya H, Naito H, Muramatsu F, Yamakawa D, Jia W, Ikawa M, Sonobe T, Tsuchimochi H, Shirai M, Adams RH, Fukamizu A, Takakura N: APJ regulates parallel alignment of arteries and veins in the skin. Dev Cell 2015, 33:247-259

12. Takakura N, Watanabe T, Suenobu S, Yamada Y, Noda T, Ito Y, Satake M, Suda T: A role for hematopoietic stem cells in promoting angiogenesis. Cell 2000, 102:199-209

13. Naito H, Kidoya H, Sakimoto S, Wakabayashi T, Takakura N: Identification and characterization of a resident vascular stem/progenitor cell population in preexisting blood vessels. EMBO J 2011, 31:842-855

14. Dhondt J, Peeraer E, Verheyen A, Nuydens R, Buysschaert I, Poesen K, Van Geyte K, Beerens M, Shibuya M, Haigh JJ, Meert T, Carmeliet P, Lambrechts D: Neuronal FLT1 receptor and its selective ligand VEGF-B protect against retrograde degeneration of sensory neurons. FASEB J 2011, 25:1461-1473

15. Franco CA, Mericskay M, Parlakian A, Gary-Bobo G, Gao-Li J, Paulin D, Gustafsson E, Li Z: Serum response factor is required for sprouting angiogenesis and vascular integrity. Dev Cell 2008, 15:448-461

16. Krimpenfort P, Ijpenberg A, Song JY, van der Valk M, Nawijn M, Zevenhoven J, Berns A: p15Ink4b is a critical tumour suppressor in the absence of p16Ink4a. Nature 2007, 448:943-946

17. Lee JY, Nakada D, Yilmaz OH, Tothova Z, Joseph NM, Lim MS, Gilliland DG, Morrison SJ: mTOR activation induces tumor suppressors that inhibit leukemogenesis and deplete hematopoietic stem cells after Pten deletion. Cell Stem Cell 2010, 7:593-605

18. Sakai H, Sagara A, Matsumoto K, Hasegawa S, Sato K, Nishizaki M, Shoji T, Horie S, Nakagawa T, Tokuyama S, Narita M: 5-Fluorouracil induces diarrhea with changes in the expression of inflammatory cytokines and aquaporins in mouse intestines. PLoS One 2013, 8:e54788

19. Sivaraj KK, Takefuji M, Schmidt I, Adams RH, Offermanns S, Wettschureck N: G13 controls angiogenesis through regulation of VEGFR-2 expression. Dev Cell 2013, 25:427-434

20. Woo KV, Qu X, Babaev VR, Linton MF, Guzman RJ, Fazio S, Baldwin HS: Tie1 attenuation reduces murine atherosclerosis in a dose-dependent and shear stress-specific manner. J Clin Invest 2011, 121:1624-1635 
21. Zhang L, Yang N, Park JW, Katsaros D, Fracchioli S, Cao G, O'BrienJenkins A, Randall TC, Rubin SC, Coukos G: Tumor-derived vascular endothelial growth factor up-regulates angiopoietin-2 in host endothelium and destabilizes host vasculature, supporting angiogenesis in ovarian cancer. Cancer Res 2003, 63:3403-3412

22. Zhang L, Takara K, Yamakawa D, Kidoya H, Takakura N: Apelin as a marker for monitoring the tumor vessel normalization window during antiangiogenic therapy. Cancer Sci 2016, 107:36-44

23. Zhang P, Hou S, Chen J, Zhang J, Lin F, Ju R, Cheng X, Ma X, Song Y, Zhang Y, Zhu M, Du J, Lan Y, Yang X: Smad4 deficiency in smooth muscle cells initiates the formation of aortic aneurysm. Circ Res 2016, 118:388-399

24. Zhang Q, Badell IR, Schwarz EM, Boulukos KE, Yao Z, Boyce BF, Xing L: Tumor necrosis factor prevents alendronate-induced osteoclast apoptosis in vivo by stimulating Bcl-xL expression through Ets-2. Arthritis Rheum 2005, 52:2708-2718

25. Sakaue-Sawano A, Kurokawa H, Morimura T, Hanyu A, Hama H, Osawa H, Kashiwagi S, Fukami K, Miyata T, Miyoshi H, Imamura T, Ogawa M, Masai H, Miyawaki A: Visualizing spatiotemporal dynamics of multicellular cell-cycle progression. Cell 2008, 132: 487-498

26. Westenskow PD, Kurihara T, Aguilar E, Scheppke EL, Moreno SK, Wittgrove C, Marchetti V, Michael IP, Anand S, Nagy A, Cheresh D, Friedlander M: Ras pathway inhibition prevents neovascularization by repressing endothelial cell sprouting. J Clin Invest 2013, 123: 4900-4908

27. Fischer C, Jonckx B, Mazzone M, Zacchigna S, Loges S, Pattarini L, Chorianopoulos E, Liesenborghs L, Koch M, De Mol M, Autiero M, Wyns S, Plaisance S, Moons L, van Rooijen N, Giacca M, Stassen JM, Dewerchin M, Collen D, Carmeliet P: Anti-PIGF inhibits growth of VEGF(R)-inhibitor-resistant tumors without affecting healthy vessels. Cell 2007, 131:463-475

28. van Hinsbergh VW, Engelse MA, Quax PH: Pericellular proteases in angiogenesis and vasculogenesis. Arterioscler Thromb Vasc Biol 2006, $4: 716-728$

29. Avraamides CJ, Garmy-Susini B, Varner JA: Integrins in angiogenesis and lymphangiogenesis. Nat Rev Cancer 2008, 8:604-617

30. Jones CA, London NR, Chen H, Park KW, Sauvaget D, Stockton RA, Wythe JD, Suh W, Larrieu-Lahargue F, Mukouyama YS, Lindblom P, Seth P, Frias A, Nishiya N, Ginsberg MH, Gerhardt H, Zhang K, Li DY: Robo4 stabilizes the vascular network by inhibiting pathologic angiogenesis and endothelial hyperpermeability. Nat Med 2008, 14: $448-453$

31. Satoh N, Yamada Y, Kinugasa Y, Takakura N: Angiopoietin-1 alters tumor growth by stabilizing blood vessels or by promoting angiogenesis. Cancer Sci 2008, 99:2373-2379

32. Fukuhara S, Sako K, Minami T, Noda K, Kim HZ, Kodama T, Shibuya M, Takakura N, Koh GY, Mochizuki N: Differential function of Tie2 at cell-cell contacts and cell-substratum contacts regulated by angiopoietin-1. Nat Cell Biol 2008, 10:513-526

33. Winkler F, Kozin SV, Tong RT, Chae SS, Booth MF, Garkavtsev I, Xu L, Hicklin DJ, Fukumura D, di Tomaso E, Munn LL, Jain RK: Kinetics of vascular normalization by VEGFR2 blockade governs brain tumor response to radiation: role of oxygenation, angiopoietin-1, and matrix metalloproteinases. Cancer Cell 2004, 6:553-563

34. Bergers G, Hanahan D: Modes of resistance to anti-angiogenic therapy. Nat Rev Cancer 2008, 8:592-603

35. Shibuya M, Claesson-Welsh L: Signal transduction by VEGF receptors in regulation of angiogenesis and lymphangiogenesis. Exp Cell Res 2006, 312:549-560

36. Chappell JC, Taylor SM, Ferrara N, Bautch VL: Local guidance of emerging vessel sprouts requires soluble Flt-1. Dev Cell 2009, 17: 377-386

37. Yang $\mathrm{H}$, Lee $\mathrm{S}$, Lee $\mathrm{S}$, Kim $\mathrm{K}$, Yang $\mathrm{Y}$, Kim JH, Adams RH, Wells JM, Morrison SJ, Koh GY, Kim I: Sox17 promotes tumor angiogenesis and destabilizes tumor vessels in mice. J Clin Invest 2013, 123:418-431

38. Corada M, Orsenigo F, Morini MF, Pitulescu ME, Bhat G, Nyqvist D, Breviario F, Conti V, Briot A, Iruela-Arispe ML, Adams RH, Dejana E: Sox17 is indispensable for acquisition and maintenance of arterial identity. Nat Commun 2013, 4:2609

39. Benedito R, Roca C, Sörensen I, Adams S, Gossler A, Fruttiger M, Adams RH: The notch ligands D114 and Jagged1 have opposing effects on angiogenesis. Cell 2009, 137:1124-1135

40. Lobov IB, Renard RA, Papadopoulos N, Gale NW, Thurston G, Yancopoulos GD, Wiegand SJ: Delta-like ligand 4 (D114) is induced by VEGF as a negative regulator of angiogenic sprouting. Proc Natl Acad Sci U S A 2007, 104:3219-3224

41. Hellström M, Phng LK, Hofmann JJ, Wallgard E, Coultas L, Lindblom P, Alva J, Nilsson AK, Karlsson L, Gaiano N, Yoon K, Rossant J, Iruela-Arispe ML, Kalén M, Gerhardt H, Betsholtz C: D114 signalling through Notch1 regulates formation of tip cells during angiogenesis. Nature 2007, 445:776-780

42. Noguera-Troise I, Daly C, Papadopoulos NJ, Coetzee S, Boland P, Gale NW, Lin HC, Yancopoulos GD, Thurston G: Blockade of D114 inhibits tumour growth by promoting non-productive angiogenesis. Nature 2006, 444:1032-1037

43. Ridgway J, Zhang G, Wu Y, Stawicki S, Liang WC, Chanthery Y, Kowalski J, Watts RJ, Callahan C, Kasman I, Singh M, Chien M, Tan C, Hongo JA, de Sauvage F, Plowman G, Yan M: Inhibition of Dll4 signalling inhibits tumour growth by deregulating angiogenesis. Nature 2006, 444:1083-1087

44. Finnson KW, Tam BY, Liu K, Marcoux A, Lepage P, Roy S, Bizet AA, Philip A: Identification of CD109 as part of the TGF-beta receptor system in human keratinocytes. FASEB J 2006, 20: $1525-1527$ 